Atmos. Chem. Phys. Discuss., 9, 3763-3809, 2009

www.atmos-chem-phys-discuss.net/9/3763/2009/

(C) Author(s) 2009. This work is distributed under

the Creative Commons Attribution 3.0 License.

\title{
Particle number emissions of motor traffic derived from street canyon measurements in a Central European city
}

S. Klose ${ }^{1}$, W. Birmili ${ }^{1}$, J. Voigtländer ${ }^{1}$, T. Tuch $^{1,2}$, B. Wehner ${ }^{1}$, A. Wiedensohler ${ }^{1}$, and M. Ketzel ${ }^{3}$

${ }^{1}$ Leibniz Institute for Tropospheric Research (IfT), Permoserstr. 15, 04318 Leipzig, Germany

${ }^{2}$ Helmholtz Center for Environmental Research (UFZ), Permoserstr. 15, 04318 Leipzig, Germany

${ }^{3}$ Department of Atmospheric Environment, National Environmental Research Institute,

Frederiksborgvej 399, 4000 Roskilde, Denmark

Received: 22 October 2008 - Accepted: 11 December 2008 - Published: 4 February 2009

Correspondence to: W. Birmili (birmili @tropos.de)

Published by Copernicus Publications on behalf of the European Geosciences Union.

\section{ACPD}

9, 3763-3809, 2009

Particle number emissions of motor traffic

S. Klose et al.

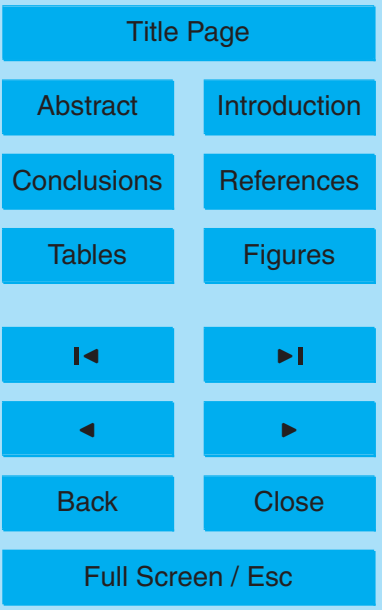

Printer-friendly Version

Interactive Discussion 


\section{Abstract}

A biennial dataset of ambient particle number size distributions (diameter range 4$800 \mathrm{~nm}$ ) collected in urban air in Leipzig, Germany, was analysed with respect to the influence of traffic emissions. Size distributions were sampled continuously in 2005 5 and 2006 inside a street canyon trafficked by ca. 10000 motor vehicles per day, and at a background reference site distant at $1.5 \mathrm{~km}$. Auto-correlation analysis showed that the impact of fresh traffic emissions could be seen most intensely below particle sizes of $60 \mathrm{~nm}$. The traffic-induced concentration increment at roadside was estimated by subtracting the urban background values from the street canyon measureTo describe the variable dispersion conditions inside the street canyon, micrometeorological dilution factors were calculated using the Operational Street Pollution Model (OSPM), driven by above-roof wind speed and wind direction observations. The roadside increment concentrations, dilution factor, and real-time traffic counts were used to calculate vehicle emission factors (aerosol source rates) that are representafluent traffic flow at speeds up to $40 \mathrm{~km} \mathrm{~h}^{-1}$. The size spectrum of traffic-derived particles was essentially bimodal - with mode diameters around 12 and $100 \mathrm{~nm}$, while statistical analysis suggested that the emitted number concentration varied with time of day, wind direction, particle size and fleet properties. Significantly, the particle number emissions depended on ambient temperature, ranging between $4.8( \pm 1.8)$ and $7.8( \pm 2.9) \cdot 10^{14} \mathrm{p}$. veh $\mathrm{km}^{-1}$ in summer and winter, respectively. A separation of vehicle types according to vehicle length suggested that lorry-like vehicles emit about 80 times more particle number than passenger car-like vehicles. Using nitrogen oxide $\left(\mathrm{NO}_{\mathrm{x}}\right)$ measurements, specific total particle number emissions of $338 \mathrm{p} .(\mathrm{pg} \mathrm{NO})^{-1}$ were inferred. The calculated traffic emission factors, considering particle number and size, are anticipated to provide useful input for future air quality and particle exposure modelling in densely populated urban areas.

\section{Particle number emissions of motor traffic}

S. Klose et al.

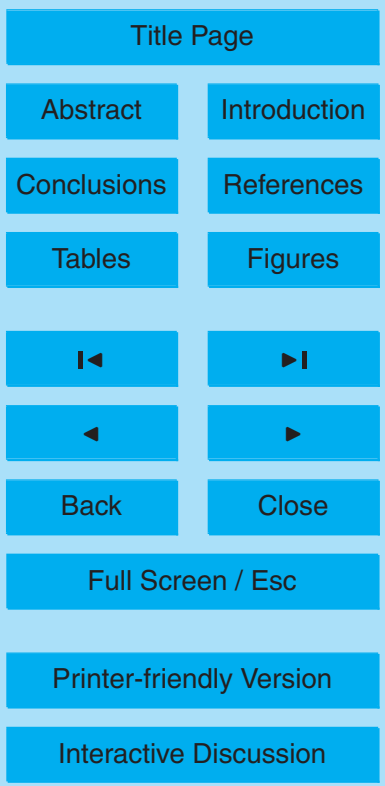




\section{Introduction}

The volume of vehicular traffic grows in almost every part of the world, impairing the environment, the quality of life, and human health by the associated emissions of noise, gases, and airborne particles (Molina and Molina, 2004; Dahl, 2005). Traffic-related

5 aerosol particles influence the global balance of atmospheric particles and their associated radiative and heterogeneous chemical effects in complex ways. Soot particles are emitted in significant quantities by diesel-powered vehicles, and lead to a warming of the atmosphere due to the absorption of shortwave radiation (Horvath, 1993; Jacobson, 2001). Furthermore, traffic-derived aerosol particles are associated with adverse 10 health effects through epidemiological studies using motor traffic emissions as an influential factor (McClellan, 1987; Cohen and Higgins, 1995; Hoek et al., 2002). A basic hypothesis for the adverse health hazards of traffic-related ultrafine $(<0.1 \mu \mathrm{m})$ and fine particles $(<1 \mu \mathrm{m})$ is that they are poorly filtered in the human respiratory tract and can deposit deep in the pulmonary alveoli (Seaton et al., 1995).

15 Populations in densely built and highly trafficked urban areas often face high pollutant and aerosol particle concentrations because of poor ventilation and air supply. Approximately $49 \%$ of the population in Germany lives in urban or densely populated areas, and are likely to be exposed to increased levels of traffic-induced aerosol particles (Voith, 2005). As more and more parts of the global population live in urban agglomerations and megacities, the environmental and health impacts of traffic are anticipated to further aggravate (United Nations, 2007). Knowledge of the characteristics and time dependent source rates of vehicle-induced emissions are necessary for efficient abatement measures.

Traffic-emitted aerosol particles usually contain several particle size fractions, most notably coarse particles resulting from abrasion and resuspension (Gehrig, 2004), and fine particles from the exhaust pipe (Abu-Allaban et al., 2003). Particulate engine emissions tend to exhibits two modes: A first mode with diameter around $100 \mathrm{~nm}$ has been identified as the soot particle mode (Kittelson, 1998), emitted notably by diesel en-

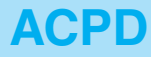

9, 3763-3809, 2009

\section{Particle number emissions of motor traffic}

S. Klose et al.

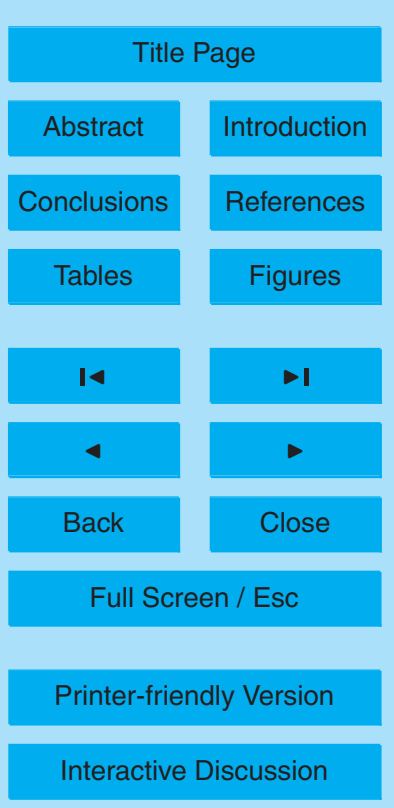


gines. A second particle mode $(<30 \mathrm{~nm})$ appears to be formed by condensation of the exhaust gas directly after emission. This mode seems to consist mainly of hydrophobic but volatile material, and is thought to result from the nucleation and condensation of unburnt fuel (Baltensperger et al., 2002; Ntziachristos et al., 2004). The emission pro5 cess of motor exhaust gas into the free atmosphere generally involves a cooling and dilution of the aerosol, which may change its properties including particle number, size, surface area and chemical composition rapidly (Kittelson et al., 2000).

Unlike in direct dynamometer measurements, the particle concentrations obtained under real driving conditions are additionally influenced by vehicle-induced turbulence, 10 varying driving conditions, outdoor temperatures, and mixed fuel composition, to mention a few. To capture the real effect of particulate traffic emissions on the environment, ambient measurements near the traffic sources are clearly necessary. On the other hand, the interpretation of roadside measurements is always aggravated by the low degree of control on the many environmental factors. Wind blowing past the traffic source as well as the turbulence induced by wind and vehicle motion usually leads to a rapid dilution of the tailpipe emissions (Zhang et al., 2004).

In a regular topography like a street canyon, however, the micro-meteorological transport is constrained by the surrounding buildings. Flow patterns and pollutant dispersal inside street canyons have therefore been studied extensively, and predictable transport patterns were identified, e.g., in the shape of vortices inside the canyon depending on the driving large-scale wind (Oke, 1998; Vardoulakis et al., 2003). Hence, street canyons are well suited for a quantification of the impact of vehicle emissions. Another relevance of street canyons lies in the usually significant portions of population that live in such areas. Traffic emissions measured here account for significant human exposures to ambient particles.

The aim of our study was to determine real-world particle emission factors for a densely built-up European city, and traffic moving at low and non-constant driving speeds - thereby extending the previous knowledge. Measurements were conducted concurrently at a roadside and a background site. The electromobility analyser mea-

\section{Particle number emissions of motor traffic}

S. Klose et al.

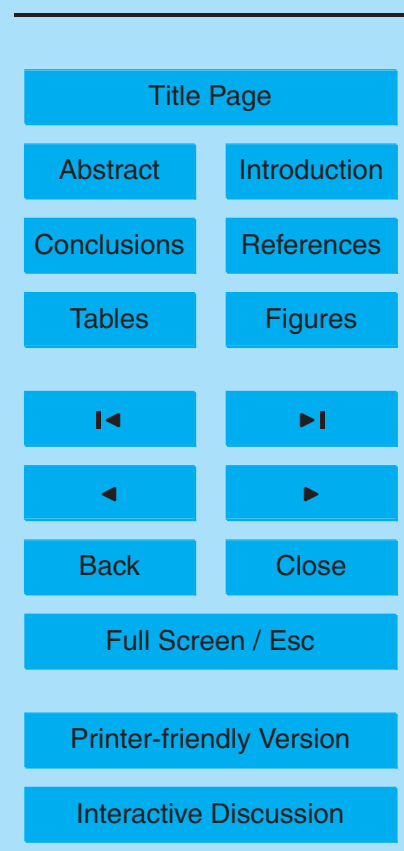


surements allow conclusions on tailpipe emissions across a wide size range and at high size resolution. Particle emission factors are derived by taking into account the meteorological dilution as calculated by a combined plume/box model. The approach is different from many other studies that have used concentration measurements in 5 tunnels, or have relied on gaseous tracers as a dilution measure. The lengthy duration of the observations (2 years) allows the extraction of statistically robust emission factors, and their differentiation after season, meteorological parameters like temperature and solar radiation, and vehicle types.

\section{Experimental and methodology}

10 Our experimental basis are two years (2005-2006) of ambient particle number size distributions that were collected in urban air in Leipzig, Germany (pop. 500 000). To distinguish between fresh traffic emissions and the existing urban background, measurements were conducted concurrently inside a trafficked street canyon, and at a second site in the urban background. The size distribution range of $4-800 \mathrm{~nm}$ encom15 passes the majority of total particle number.

\subsection{Measurement sites}

The street canyon site Leipzig-Eisenbahnstrasse ("Leipzig-Eiba" in the following) is an atmospheric research station jointly operated by the Leibniz Institute for Tropospheric Research (IfT) and the Helmholtz Centre for Environmental Research (UFZ). The street canyon is within a densely built-up residential area, characterised by multi-storey period buildings (see Fig. 1). The street canyon is regular in that its aspect ratio is close to unity (height: $18 \mathrm{~m}$, width: $20 \mathrm{~m}$ ), and no building gaps are present. During our observation period, Eisenbahnstrasse street carried about 10000 vehicles per workday. The aerosol inlet is mounted at a height of $6 \mathrm{~m}$ above street level on the canyon's northern side. While a limited period of data was discussed by Voigtländer et al. (2006), this

Particle number emissions of motor traffic

S. Klose et al.

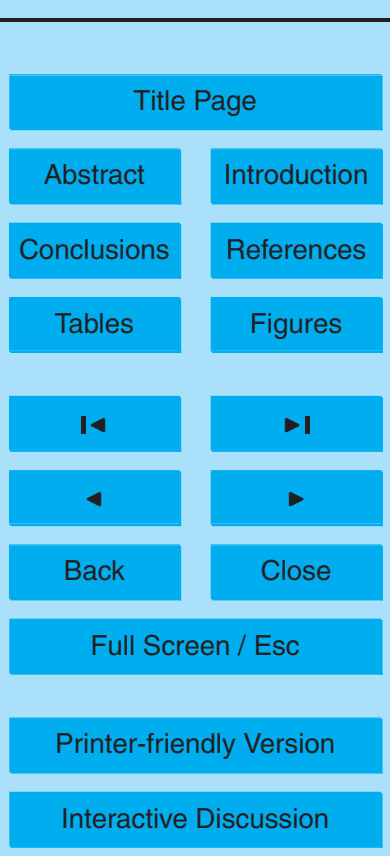

Interactive Discussion 
work makes use of a much longer part of the size distribution data set.

To provide a background measure of particle size distributions, measurements were also conducted continuously at the atmospheric research station Leipzig-IfT, situated on the roof of IfT's institute building. Here, aerosol particles are sampled at a height 5 of $16 \mathrm{~m}$ above the ground. Under westerly winds, Leipzig-IfT is located $1.5 \mathrm{~km}$ downstream Leipzig-Eiba, but distant from any road by at least $100 \mathrm{~m}$. Earlier work on aerosol particle and trace gas concentrations has characterised Leipzig-IfT as an urban background site (Wehner and Wiedensohler, 2003), with the exception of localized emissions from a heat supply station from southerly wind directions. Data con10 taminated by the latter source (about $3 \%$ of the total amount of data) were generally excluded from the analysis.

\subsection{Size distribution measurements}

At both measurement sites (Leipzig-Eiba, and Leipzig-IfT), particle number size distributions in a size range 3-800 $\mathrm{nm}$ were measured using identical twin differential mobility particle sizers (TDMPS). Both instruments were based on the parallel combination of two differential mobility analysers described in Birmili et al. (1999). Particles were classified in a sheath air with a relative humidity below $5 \%$. Ten minutes were required for a full size distribution. As the count rates in the size channels 3.0 and $3.5 \mathrm{~nm}$ of both instruments were zero most of the time - likely the result of diffusional losses in the inlet systems, no meaningful results could be derived from these measurements. Consequently, the diameter range was generally truncated to $4-800 \mathrm{~nm}$ for all results discussed in this paper.

At Leipzig-Eiba, sample aerosol was drawn through a membrane dryer and a buffering volume. The latter measure was taken to smoothen the short-term fluctuations caused by individual vehicles passing through the street canyon. The particle losses in this inlet system (ascribed mainly to Brownian diffusion of small particles) were quantified by a on-site comparison experiment with an additional particle size spectrometer. The comparison revealed particle losses (40-80\%) mainly in the 4-20 nm size range,

\section{Particle number emissions of motor traffic}

S. Klose et al.

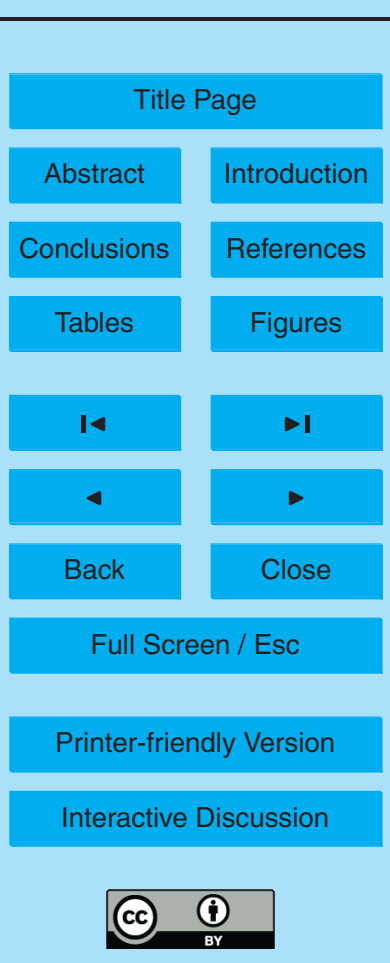


which were accounted for when preparing the final size distributions. The TDMPS at Leipzig-IfT exhibited a reduced counting efficiency in the range of small particles $(<30 \mathrm{~nm})$, when compared directly against Leipzig-Eiba's TDMPS instrument during a two-week experiment. This reduced efficiency was also accounted for in the prepara5 tion of the final measurement data.

After these instrumental corrections, the long-term time series of both instruments showed occasional diverging long-term trends with respect to particle number concentration, even during periods of practically zero traffic. After a careful and detailed examination of the data, we came to the conclusion that drifts in the instrumental flow 10 calibrations were responsible. As a result, the size distributions at Leipzig-IfT were adjusted by a final time-dependent correction factor, which was based on the assimilation of both time series for the "zero emission scenario", which was defined as the traffic-deprived night-time period (02:00-03:00 LT), wind speeds above $2 \mathrm{~m} \mathrm{~s}^{-1}$, and considering the concentrations of long-lived particles $(>300 \mathrm{~nm})$ only.

\subsection{Traffic, wind, and $\mathrm{NO}_{\mathrm{x}}$}

To relate the particle concentrations with traffic density, vehicles were counted using an automated video detection system (Autoscope Rackvision, Image Sensing Systems (ISS), St. Paul, MN, USA). The camera was positioned at a height of $10 \mathrm{~m}$ on the front of the building housing the Leipzig-Eiba research station. The number of vehicles was determined by the change in contrast caused by moving vehicles, with vehicles being classified by length and height into two main categories: "lorry-like" and "passenger car-like". These two categories roughly correspond to the HDV (heavy duty vehicles) and LDV (light duty vehicles) categories, but cannot be considered equivalent since only the vehicle length could be employed as a criterion in our study. On workdays the relative share of lorry-like vehicles was about $4 \%$. An intermediate class of vehicles, comprising transport vans and delivery cars would usually be classified as passenger car-like vehicles by the detection system.

A validation of the automatic readings by episodic manual counts showed a satis-

\section{Particle number emissions of motor traffic}

S. Klose et al.

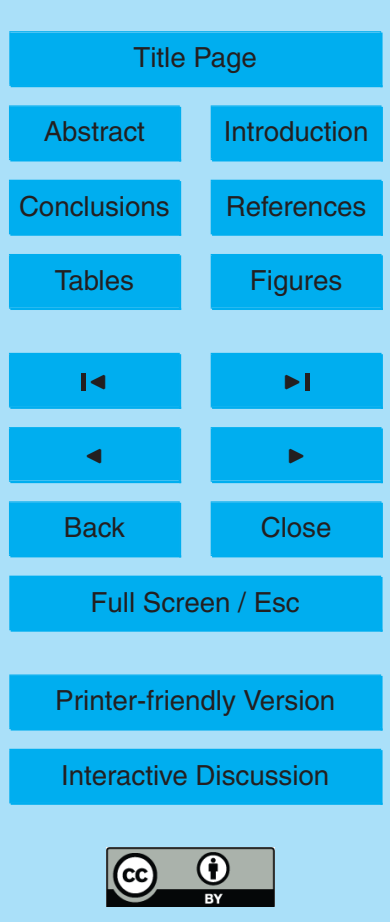


factory agreement with respect to both, the counting and classification of passenger car-like vehicles (divergence in vehicle number ca. 3\%). Problems with vehicle classification, however, occurred during darkness due to moving light cones and shadows. This led to an overestimation of the actual traffic density. To ensure vehicle emission 5 factors at high accuracy, only traffic counts registered during daytime are used throughout this paper for computational purposes. The typical vehicle speed was not detected automatically but estimated to be $30 \mathrm{~km} \mathrm{~h}^{-1}$ from self-driving experiences.

Traffic lights are installed at the crossing of the two streets seen in Fig. 1 (Eisenbahnstrasse and Hermann-Liebmann-Strasse). Therefore, the traffic contributing to 10 the concentrations measured at Leipzig-Eiba consisted partly of stop-and-go-traffic, but also of rolling queues of vehicles at speeds of $30 \mathrm{~km} \mathrm{~h}^{-1}$, and individual vehicles at up to $40 \mathrm{~km} \mathrm{~h}^{-1}$. Owing to the limited time resolution of our TDMPS measurements, it was not possible to attribute different emission rates to these traffic modes. The emission factors presented in this paper are considered as values that are averaged over these traffic modes.

3-D wind speed and wind direction were measured at Leipzig-Eiba at $30 \mathrm{~s}$ time resolution using an ultrasonic anemometer (model USA-1, Metek GmbH, Elmshorn, Germany). The wind sensor was placed $4 \mathrm{~m}$ above the roof top of the five storey building where particle measurements were made. Nitrogen Oxygen Analysers (model 8841, Monitor Labs) were used to measure $\mathrm{NO}$ and $\mathrm{NO}_{2}$ both at Leipzig-Eiba, and Leipzig-IfT. Temperature and global radiation measurements for the entire period were kindly supplied by the Institute of Meteorology of the University of Leipzig, located at a distance of $4.5 \mathrm{~km}$.

\subsection{Dispersion modelling with OSPM}

25 In our work we employed the Operational Street Pollution Model (OSPM) as the main tool to determine the dilution of traffic aerosols downstream the traffic source. OSPM was developed by the National Environmental Research Institute of Denmark (http://ospm.dmu.dk) and is particularly suited for regular street canyons, as is the case

\section{Particle number emissions of motor traffic}

S. Klose et al.

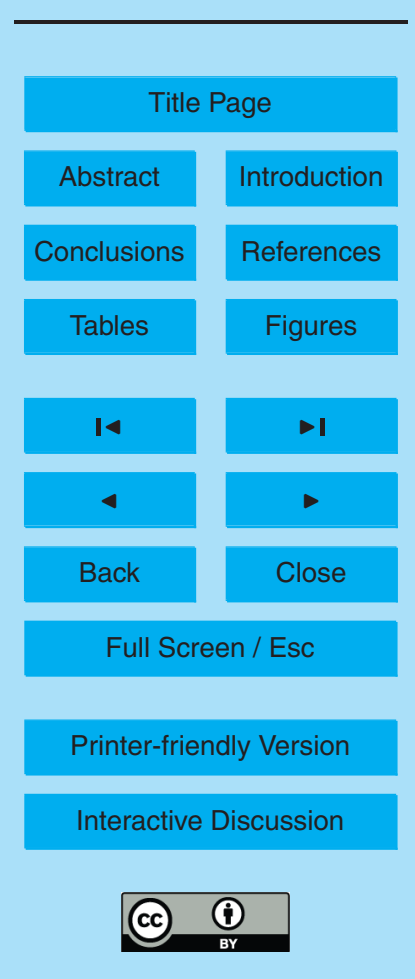


here. OSPM combines a plume model to calculate the dilution on the direct way from the tailpipe to the particle inlet and a box model for the dilution in the part of the street canyon where the vortex is present (Berkowicz et al., 1997). The dilution simulated by OSPM depends, among others, on the turbulence induced by both, the large scale 5 wind, and the flow of vehicles. OSPM requires an implementation of the topography of the street canyon (orientation, height, width, distance to next crossing streets and height of the particle inlet; cf. Fig. 1), while meteorological, traffic and aerosol parameters are commonly processed as hourly average values.

OSPM calculates a traffic-related concentration increment $N_{\text {sim }}\left(\right.$ in p. $\mathrm{cm}^{-3}$ ) by

${ }_{10} N_{\text {sim }}=Q \cdot F$,

with $Q$ being the line source intensity of traffic (in p. $\mathrm{m}^{-1} \mathrm{~s}^{-1}$ ), and $F$ being the meteorological dilution factor (in $\mathrm{sm}^{-2}$ ). $F$ is simulated particularly as a function of wind speed, wind direction, and vehicle speed. In contrast to its denomination as a "dilution factor", it is proportional to the concentration expected at the receptor point. For for15 ward simulations, $Q$ can be assumed either as unity, or as a value taken from previous experience or a literature source.

These simulated concentrations can be compared to the experimentally determined roadside increment

$N_{\text {exp }}=N_{\text {roadside }}-N_{\text {background }}$,

20 where background values are subtracted from roadside measurements. If the forward simulations adequately represent the experimentally observed changes, the dilution factor $F$ can be used to determine emission factors in a procedure termed inverse modelling (Palmgren et al., 1999; Ketzel et al., 2003).

The emission factor $E$ (in p. veh ${ }^{-1} \mathrm{~km}^{-1}$ ) is defined as the line source intensity nor25 malised by the traffic density. Using Eq. (1) it can be written as

$$
E=Q / M=N_{\exp } /(F \cdot M)
$$

Particle number emissions of motor traffic

S. Klose et al.

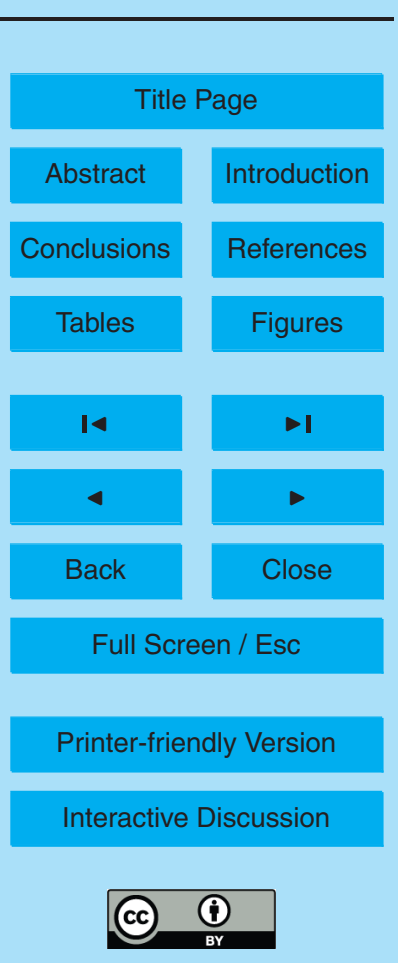


with $M$ being the traffic density $\left(v^{-1} \mathrm{~s}^{-1}\right)$. $E$ indicates how many particles (or pollutants) are emitted by an average vehicle of the vehicle fleet per kilometre driven, under the given driving conditions. Since our model simulations do not involve an explicit modelling of aerosol dynamical processes, the calculation of the emission factor 5 requires that the pollutants (particle population) can be considered inert during the transport between the source and the receptor station. The life-time of aerosol particles with respect to coagulation has been tested with the aid of multiple site measurements within the street canyon and a simplistic aerosol dynamics model calculation (not shown here). We alternatively refer to life-time calculations against coagulation made for an even higher concentrated traffic aerosol (Birmili et al., 2008), and the results obtained from complete aerosol dynamics simulations (Pohjola et al., 2003; Zhang et al., 2004). The conclusion is, in any case, that the particle number concentration (diameter $>10 \mathrm{~nm}$ ) can be considered inert during the residence time within the street canyon.

\section{Phenomenological results}

\subsection{Observed particle size distributions and number concentrations}

The combined weekly and diurnal cycles of particle number concentrations and traffic density are displayed in Fig. 2. Particle number size distributions were integrated over five size intervals $(4-10,10-30,30-60,60-300$, and 300-800 nm), which were defined on the basis of the autocorrelation analysis shown below (Fig. 4) and a correlation analysis (not shown) implying statistical independence. $N_{\left[D_{p 1} ; D_{p 2}\right]}$ will denote the number concentration in the size interval $D_{p 1} \ldots D_{p 2}$ in the following. Since $N_{[30 ; 60]}$ and $N_{[60 ; 300]}$ correlated significantly $\left(R^{2}=0.77\right)$, they were combined in Fig. 2 b. Also, $N_{[300 ; 800]}$ showed a significant correlation with the total particle volume $<800 \mathrm{~nm}\left(R^{2}=0.97\right)$ so that the latter parameter was not displayed either.

The street canyon concentrations (Leipzig-Eiba) show an pronounced diurnal cycle

\section{Particle number} emissions of motor traffic

S. Klose et al.

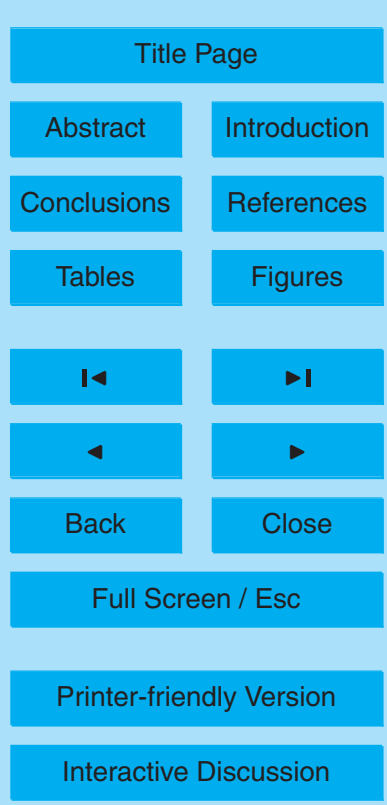


as a result of the local traffic. The intensity of the diurnal signal diminishes with increasing particle size (Fig. 2b). At the urban background site Leipzig-IfT, a diurnal variation is pictured as well, although much less intense than in the proximity of the street canyon traffic. The number concentrations are time-correlated with traffic density, especially $5 N_{[10 ; 30]}$ and $N_{[30 ; 60]}$.

The daily maxima in particle number and traffic density do, however, not coincide: On workdays (defined as Monday-Friday hereafter) the total traffic density peaks at about 17:00 LT in the afternoon. $N_{[10 ; 30]}, N_{[30 ; 300]}$ and $N_{[300 ; 800]}$, however, reach their maximum duringthe morning peak traffic period (about 09:00 LT). An accepted expla10 nation for their maximum in the morning is the reduced vertical mixing at that time, which leads pollution trapping in the shallow urban surface layer (Schäfer et al., 2006). Throughout the day the mixed layer increases, so that the steady-state concentrations of pollutants near the ground decrease even if the intensity of the pollution source is maintained. A second point is that the relative share of lorry-like vehicles, which are known to emit a manyfold of the emissions of passenger car-like vehicles is greater in the morning. On the weekends, the traffic volumes are substantially lower, and also time-delayed (Fig. 2). These lower source intensities manifest themselves in accordingly lower aerosol concentrations, especially in the street canyon (Fig. 2b).

$N_{[4 ; 10]}$ behaves differently from the rest of the particle size intervals in that it peaks around noon (about 12:00 LT). The reason is that $N_{[4 ; 10]}$ is influenced to a greater extent by a source different from traffic, secondary formation from vapours that are generated by photochemical processes (Kulmala et al., 2004). During a detailed multiple-site study across the city of Leipzig we were able to show that the spatial scale of that photochemically driven nucleation can well encompass the area of the entire city and beyond (Costabile et al., 2008).

To illustrate the particle number size distributions occurring during the morning peak traffic hour, Fig. 3 compiles median number size distributions between 08:00 and 09:00 LT on workdays (Monday-Friday) for the complete time period 2005-2006. Although the influence of the local traffic emissions are detectable across the entire parti-

\section{Particle number emissions of motor traffic}

S. Klose et al.

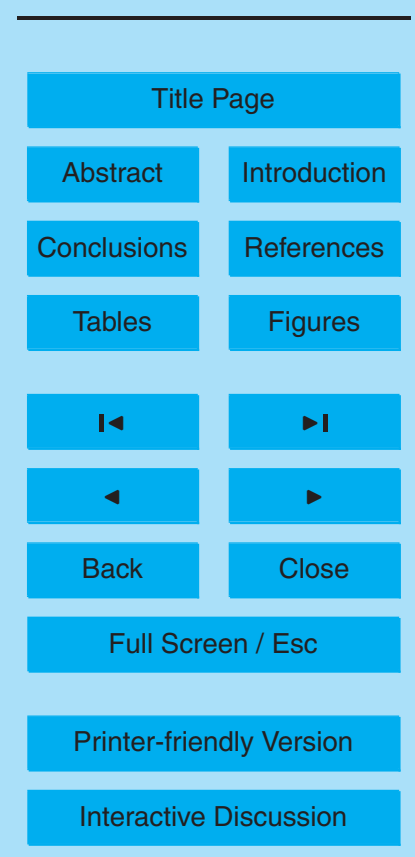


cle size spectrum, it appears most pronounced at the lower end of the size distribution.

To provide a generally accessible version of the data, tri-modal lognormal distributions were fitted to the experimental size distributions using a least-squares algorithm. The fitting results for the mean diurnal cycle on workdays are presented in Table 1, and 5 their position indicated for the special case 08:00-09:00 LT in Fig. 3. From the Table it is evident that the nucleation mode dominates the total particle number concentration at both sites, and throughout the whole day. At Leipzig-Eiba the nucleation mode reaches its maximum concentration between 14:00-16:00 LT, exceeding the Aitken mode by a factor of 3.3 and the accumulation mode by 8.4. A similar case can be seen for LeipzigIfT, however with reduced factors of 2.0 and 5.8 , respectively.

It is worth to note that our aerosol observations here are not unique; particle size distributions at urban roadside locations have been observed in numerous scientific studies before albeit truelong-term observations (Charron and Harrison, 2003; Ketzel et al., 2003; Hueglin et al., 2006) have remained scarce.

\subsection{Autocorrelation}

To scrutinise the time-dependent behaviour of the street canyon aerosol, the autocorrelation coefficient $r_{x x}$ was calculated as a function of the time lag $\tau$ (integer multipleof $\Delta t)$ :

$r_{x x}(\tau)=\sum_{t=0}^{n} x(t) \cdot x(t+\tau)$

20 with $x(t)$ being the discrete, time and diameter channel dependent function $x(t)=d N / d \lg D_{p}\left(t, D_{p}\right)$ from Leipzig-Eiba and $n$ being the total number of data points included.

Figure 4 shows the autocorrelation coefficient $r_{x x}$ for a selection of six particle diameters that show a distinct behaviour. Nucleation mode particles ( 6 and $17 \mathrm{~nm}$ ) show the most intense diurnal cycle, which can be seen by the maxima of $r_{x x}$ at multiples of one

\section{Particle number emissions of motor traffic}

S. Klose et al.

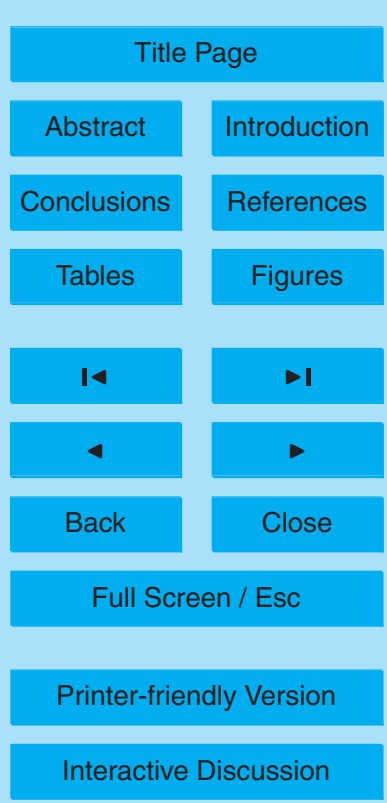


day. Particles of these sizes are generated either by the traffic, or by photochemically induced new particle formation, which both underlie a diurnal cycle. A weekly cycle exists for 6 and $17 \mathrm{~nm}$ particles as well because $r_{x x}$ reaches relative maxima at lag times of 7 and 14 days. The presence of a weekly cycle is an unmistakable hint towards an5 thropogenically driven source effects. Aitken mode particles $(53 \mathrm{~nm})$ have a significant diurnal cycle as well, although in a less pronounced fashion. For $53 \mathrm{~nm}$-particles, $r_{x x}$ shows additional side maxima at non-integer time lags of $1.5,2.5,3.5$. These side maxima result from the double-peaked structure of the diurnal cycle involving maxima both in the morning and the afternoon (Fig. 2b).

With increasing particle size, the diurnal periodicity becomes less pronounced, as is visible in the accumulation mode (390 and $693 \mathrm{~nm}$ in Fig. 4). It is clear that the longer life-times of accumulation mode particles makes their concentrations vary on the scale of days rather than $24 \mathrm{~h}$. Meteorological cycles, such as the subsequent passages of low/high pressure areas tend to average out during extended data coverage. It can be 15 noted that also the $r_{x x}$ of accumulation mode particles exhibit side maxima at lag times of 14 and 21 days, which are indicative of a weekly cycle of anthropogenic emissions.

To quantify the relative importance of periodic versus persistent time-behaviour in the data, the autocorrelation coefficients $r_{x x}$ were approximated in a least-squares fit by a superposition of the following functions:

20 $y=A \exp \left(-t_{A} \cdot \tau\right)+B \cos (2 \pi \cdot \tau)+C \cos (2 \pi / 7 \cdot \tau)+(1-A-B-C)$.

Here, the first term describes the persistent component (exponential decay), the second term the diurnal variation (cosine wave with period time $1 \mathrm{~d}$ ), the third term the weekly variation (cosine wave with period time $7 \mathrm{~d}$ ), and the fourth term a constant that is constructed so that $r_{x x}(0)=1$ is fulfilled. The absolute values of the first three com25 ponents were integrated over the lag time range 0-21 d yielding the integral values $F_{A}$, $F_{B}$, and $F_{C}$ representing their relative importance in the analysed time series.

Figure 5 shows $F_{A}, F_{B}$, and $F_{C}$ as a function of particle diameter. It is evident that the essentially diurnal behaviour of particles falls into the size range $4-20 \mathrm{~nm}\left(F_{B}>1.5\right)$, an

Particle number emissions of motor traffic

S. Klose et al.

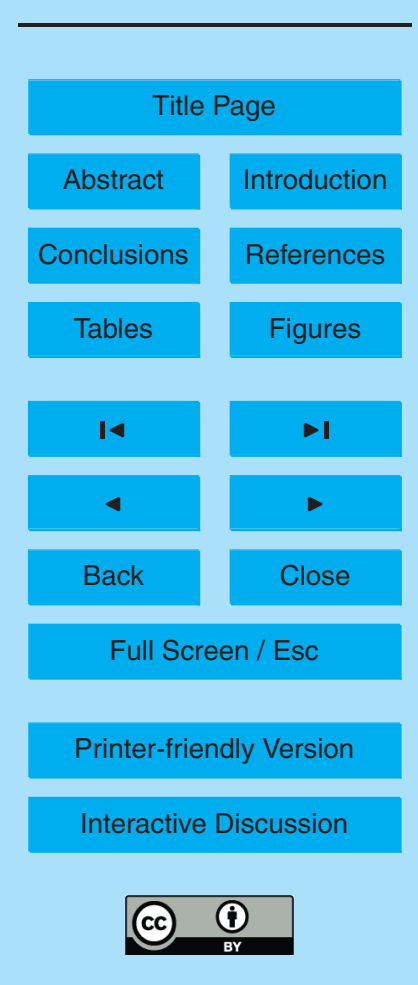


effect which is most pronounced at $8 \mathrm{~nm}\left(F_{B}=4.5\right)$. At $60 \mathrm{~nm}$, the integral value $F_{A}$ of the persistent autocorrelation component reaches that of the diurnal component, and increases above this diameter. It is therefore our interpretation that aerosol particles with a life-time of more than one day dominate the concentrations above $60 \mathrm{~nm}$.

5 The weekly periodic component has a generally lower amplitude than the diurnal component, but also depends sensitively on particle size. We scrutinise on the ratio $F_{C} / F_{B}$ in the nucleation mode range, since it can provide information on the relative importance of particle processes that are driven purely anthropogenically (weekly component) and driven both meteorologically and anthropogenically (diurnal compo10 nent). The ratio $F_{C} / F_{B}$ is about 0.2 for $D_{p}=20 \mathrm{~nm}$, and decreases with decreasing particle size. Concretely, the weekly component recedes behind a rather pure diurnal dependency. We take this as an indication that especially the concentrations of particles smaller than $10 \mathrm{~nm}$ are controlled by meteorologically-driven processes (including photochemical particle production) than by the weekly cycle of traffic emissions.

\section{Evaluation of the OSPM model performance}

This section illustrates the quality of particle concentration simulations in the street canyon using the OSPM model (Sect. 2.4). To compute the dispersion of traffic aerosol by means of the dilution factor $F$, information on the topography of the measurement site, hourly mean values of wind direction, wind speed, traffic density and traffic speed are used for model initialisation. For a first model evaluation, a line source intensity $Q$ (in p. $\mathrm{m}^{-1} \mathrm{~s}^{-1}$ ) for the traffic in the Eisenbahnstrasse street canyon was constructed based on a particle number emission factor $\left(4.9 \cdot 10^{14} \mathrm{p} . \mathrm{veh}^{-1} \mathrm{~km}^{-1}\right)$ determined from previous short-term aerosol observations (Rose et al., 2006).

Figure 6 compares the simulated particle number concentrations (roadside increment) and the corresponding observations for a 2-week period in September and October 2006. The covariation between the simulated and experimental values was considered satisfactory in that the model reproduced the daily cycles as well as dif-

Particle number emissions of motor traffic

S. Klose et al.

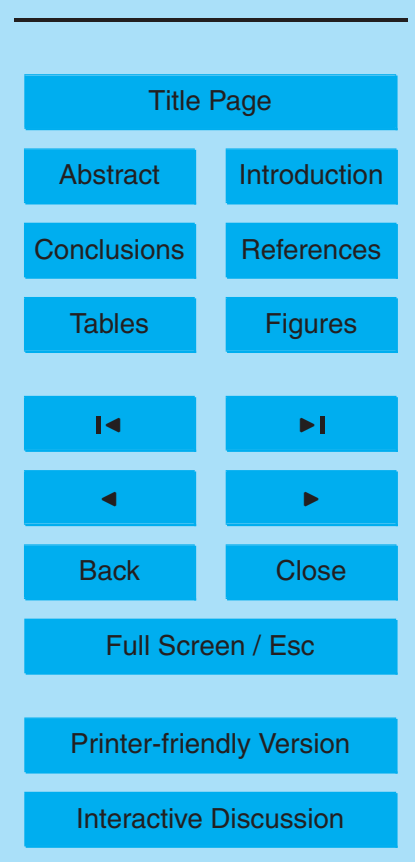


ferent levels of peak concentrations under changing wind directions and wind speeds (Fig. 6a). The measure of determination $\left(R^{2}\right)$ for the linear correlation was 0.6 for the original hourly data, and improved to 0.79 when taking a rolling four-hour average.

Our conclusion has been that OSPM yields reliable results for regular street canyons

5 like Leipzig-Eiba (this work), and Copenhagen-Jagtvej (Ketzel et al., 2003). In order to stretch its application to environments of a more irregular topography, OSPM was also tested for a total of five additional roadside observation sites in Leipzig that were operated temporarily during an intensive field experiment in 2005 (Costabile et al., 2008). A particular conclusion was that OSPM produced reliable time series of roadside concen10 trations as long as one side of the road was was fully covered with buildings. Another result was that reliable traffic emission factors could only be determined from roads that showed a certain minimum traffic volume, estimated around 5000 vehicles per day.

\section{Traffic emission factors from inverse modelling}

Traffic emission factors $E$ were calculated from a combination of the experimental road15 side increment concentration and the dilution factors as explained in Sect. 2.4 (inverse modelling).

\subsection{Diurnal cycle}

Figure 7 shows the diurnal cycle of the total particle number emission factor $E$ for the average fleet at Leipzig-Eiba in 2005/2006. Different percentiles are indicated to 20 illustrate the range of observations. Median values of $E$ within a rather narrow range between 7 and $10 \cdot 10^{14} \mathrm{p}$. veh ${ }^{-1} \mathrm{~km}^{-1}$ can be observed between 06:00 and 22:00 LT. This constancy is, at first glance, consistent with the small observed changes in the composition of the vehicle fleet during that period.

Higher values of $E$ can, however, be noticed for the early morning hours (03:0025 06:00 LT), with $E$ being roughly twice as large as during day-time. This effect is not

\section{Particle number emissions of motor traffic}

S. Klose et al.

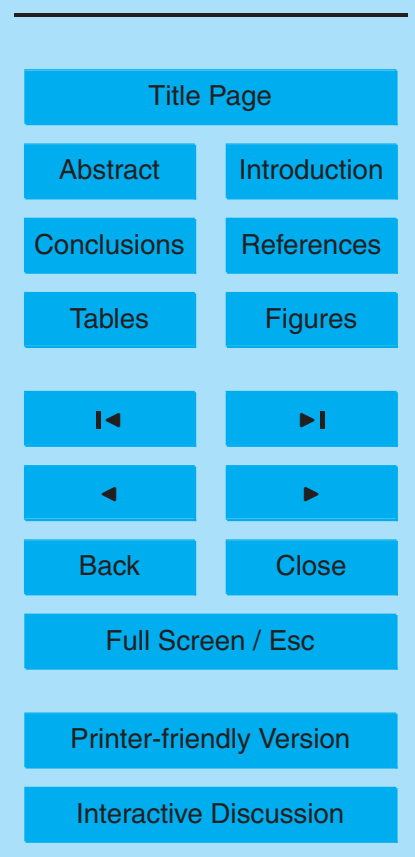


straightforward to explain. Importantly, the early morning maximum occurs in calculated $\mathrm{NO}_{\mathrm{x}}$ emission factors as well, i.e. it is not a dedicated particle effect.

Vehicle counts collected during darkness are associated with errors. However, the video detection system only tends to overestimate the traffic density under poor-lit con5 ditions, so that this error would lead to underestimation of the real emission factor rather than an overestimation. Therefore, possible miscounts of the traffic density cannot explain this overestimation in $E$.

An increase in $E$ could be caused by an increased fraction in lorry-like vehicles or diesel passenger cars, which are known to generate higher emissions. In Copenhagen 10 Ketzel et al. (2003) attributed their early-morning maximum by the prevalence of diesel taxis during the night. Although this rationale could also be valid for our street canyon in Leipzig, we have no reliable fleet composition measurements to verify this hypothesis.

Importantly, the maximum $E$ occurs between 03:00 and 04:00 LT, a time when the traffic density $M$ is near its all-day minimum. This alone causes $E$ to be highly uncer15 tain, since a low observed particle number is divided by another small number in the equation $E=N_{\exp } /(F \cdot M)$. The intensity of traffic-induced turbulence will also reach an all-day low, and consequently, any deviations between OSPM's dispersion simulation and the real flow field will propagate more strongly into the calculated $E$.

Another observation is that the average wind speed has its all-day low between 02:00 20 and $04: 00 \mathrm{LT}, 1.9 \mathrm{~m} \mathrm{~s}^{-1}$, compared to a maximum of $2.5 \mathrm{~m} \mathrm{~s}^{-1}$ in the afternoon. The wind speed, which is measured above roof-level, enters into the calculation of the dilution factor $F$ and should therefore play no role for the magnitude of $E$.

A final argument could be the negligence of thermally induced stratification in the model simulations. OSPM generally assumes a neutrally stable atmosphere. Between 03:00 and 04:00 LT, the lowest layers of the atmosphere tend to be stratified due to radiative cooling. As long as the buildings act as a thermal sink, the air in the street canyon will also stabilize during the night. It can be thought that due to such stratification in the canyon, air exchange between the layer aloft and the canyon might be inhibited. Thus, the wind speed measurement above roof-top level might overestimate

\section{Particle number emissions of motor traffic}

S. Klose et al.

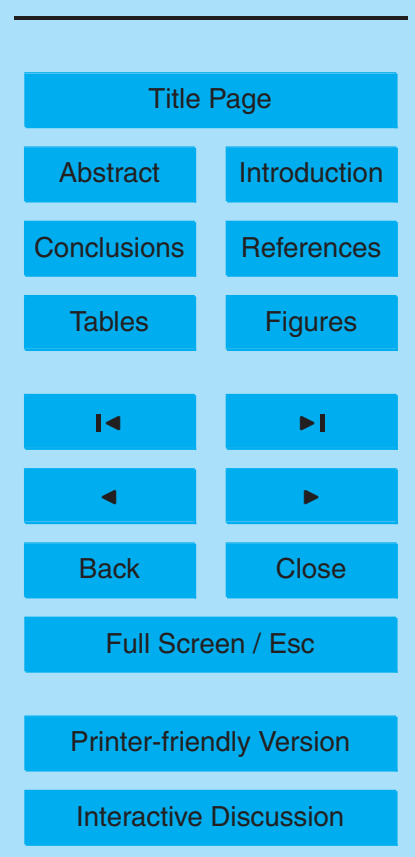


the flow velocities inside the canyon and thus lead to an underestimation of the dilution factor $F$. The whole process would lead to an overestimation of the emission factor $E$, such as observed in Fig. 7.

Even after reviewing the above discussion, we could not explain the occurrence of 5 the early morning peak with certainty. As a consequence, we will concentrate on traffic emission factors calculated from daytime measurements in the following, i.e. when the traffic densities were high, and the results unquestionable.

\subsection{Dependency on wind direction}

Particle number emission factors were calculated on the basis of the number of vehicles that pass directly in the front of the measurement site. Traffic emissions from nearby roads are neglected in the calculation, but could possibly enhance the measured concentrations and therefore the calculated emission factor. To identify possible effects from nearby streets the dependency on wind directions was analysed (see Fig. 8). Increased emission factors occurred especially under westerly wind directions. A closer inspection yielded that in the sector $225-315^{\circ}$ the mean emission factor was about 1.7 times higher than in the remaining sector. As illustrated in Fig. 1 the street canyon Eisenbahnstrasse is intersected by the another trafficked street (Hermann-LiebmannStrasse) $30 \mathrm{~m}$ to the west of the measurement site. This street represents the largest single additional particle source in the surroundings. Manual traffic counts confirmed traffic numbers and fleet compositions that were roughly equivalent to those in Eisenbahnstrasse street.

To assess the role of the Eisenbahnstrasse/Hermann-Liebmann-Strasse intersection more thoroughly a full 3-D transport model (All-scale Atmospheric Model) was applied simulating the emissions from both streets separately. The model follows the technical description given in Birmili et al. (2008), and was applied to a grid area of about $100 \times 150 \mathrm{~m}$, roughly encompassing an area twice as big as that shown in Fig. 1 . The 3-D simulation suggested that depending on the wind direction between 0 and $74 \%$ of the traffic-derived aerosol concentration at Leipzig-Eiba originates from Hermann-

\section{Particle number emissions of motor traffic}

S. Klose et al.

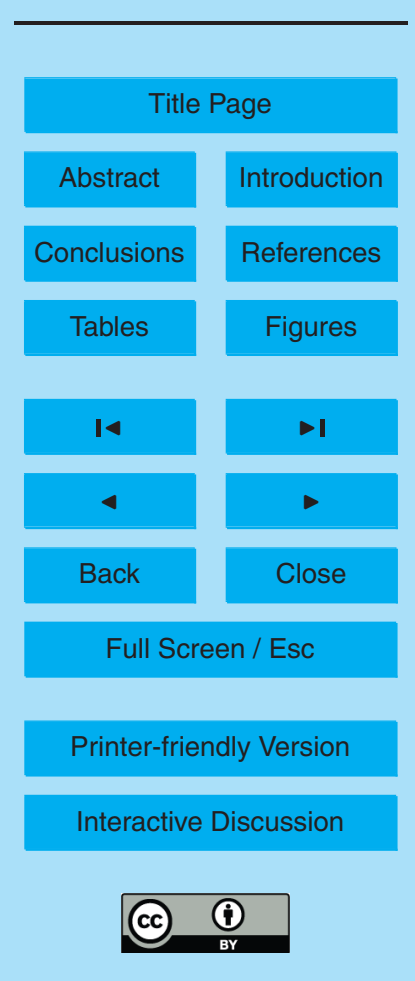


Liebmann-Strasse, with a maximum from westerly and southwesterly wind directions. It is planned to publish details on these simulations within a forthcoming article.

Since emissions from the Hermann-Liebmann-Strasse street obviously enhance the emission factor $E$ for specific wind directions, all further analyses will exclude the data 5 from the westerly/southwesterly sector $225-315^{\circ}$.

\subsection{Dependency on solar radiation and ambient temperature}

Solar radiation and/or ambient temperatures may influence particle formation and particle transport in the street canyon directly (thermodynamically) or indirectly, i.e. through thermal turbulences not considered in the OSPM model. Therefore, the sensitivity of the emission factors against changes in radiation intensity and temperatures was checked. First, we segregated all periods when at least two thirds of the building wall above the particle inlet were sunlit, which - owing to the astronomical and topographical conditions, was only possible between 1 June and 31 August. The estimation of the sunlit periods, which are associated with periods of additional thermal convection 15 within the street canyon, was made on the basis of direct solar radiation measurements (derived from global and diffuse sky radiation) by the Institute of Meteorology of the University of Leipzig. As a matter of fact, there was no significant difference between emission factors calculated at sunny or non-sunny conditions (fluctuations within the standard deviation), which implies that wind-driven and vehicle-induced air motion are the dominating transport mechanisms in the street canyon.

Second, we tested the emission factors for a dependency on ambient temperature. Assuming constant engine operation, decreasing ambient temperatures increase the supersaturation ratio of condensable vapours in the traffic exhaust, which may lead to an increase in the number of particles in the nucleation mode. Lower temperatures can also cause precursor gases to condense more rapidly on already existing particles, leading to particle growth. While these two effects have been investigated in laboratory studies (Shi and Harrison, 1999; Abdul-Khalek et al., 2000), we could assess them under the given urban driving conditions: Fig. $9 a-b$ illustrates a clear negative correlation

Particle number emissions of motor traffic

S. Klose et al.

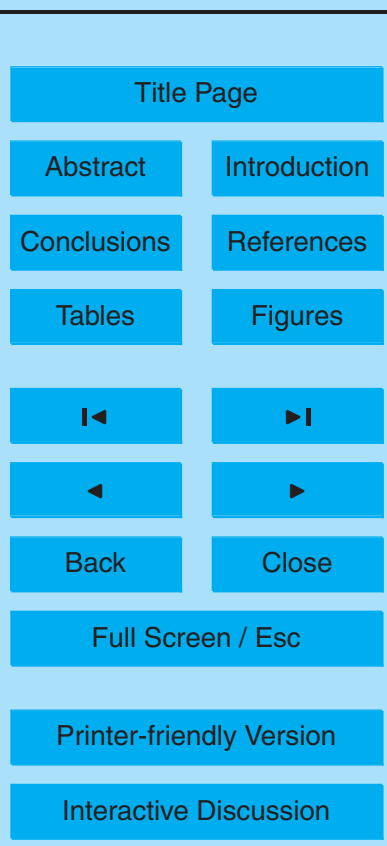


for particles in the lower size ranges $(4-10 \mathrm{~nm} ; 10-30 \mathrm{~nm})$ with statistically significant slopes of a linear regression analysis, given by the regression probability $p$ which is far below $0.1 \%$. We take this as indicative of the particle emission factor being influenced by new particle formation processes which, in turn, depend on ambient temperatures

5 for thermodynamic reasons. Particle size ranges over $30 \mathrm{~nm}$ show no significant relationship with ambient temperature (Fig. 9c; $p=59 \%$ ), which agrees with earlier findings that the number emissions of the directly emitted solid particles (soot) are less prone to changes in ambient temperature (Mathis et al., 2005).

The emission factor of total particle number $(4-800 \mathrm{~nm})$ could be expressed as a 10 linear function of temperature $T$. (From thermodynamics we would actually not expect a linear but an exponential dependency - an experimental confirmation for a specific type of functional dependency can, however, not be expected within the uncertainties of the present data analysis.) Concretely, the parameterised linear temperature dependency was $E(T)=E\left(T_{0}\right) \cdot(1.28-0.02 \cdot T)$ with $T_{0}=15^{\circ} \mathrm{C}$ and is valid for the finite 15 temperature range $-10^{\circ} \mathrm{C}<T<35^{\circ} \mathrm{C}$. Our findings for the temperature dependency of traffic-related particle number are in line with similar observations in street canyons in Copenhagen, Denmark Palmgren et al. (2003) and Stockholm, Sweden (Olivares et al., 2007).

\subsection{Size distribution of the emission factor}

20 An average size distribution of the emission factor was computed after excluding data measured at westerly wind directions (225-315 ; cf. Sect. 5.2) and concentrating on periods with significant traffic density (workdays, 08:00-18:00 LT). Number and volume distributions (assuming spherical particles) are displayed in Fig. 10. In contrast to the measured number size distribution at Leipzig-Eiba, a mainly bimodal distribution could 25 be detected both, for the number and volume size distributions of $E$. The volume distribution illustrates that the majority of particle volume (and thus also mass) concentration is emitted in the size range $>100 \mathrm{~nm}$.

Integration across the whole number size spectrum yields an emission factor for an

\section{Particle number emissions of motor traffic}

S. Klose et al.

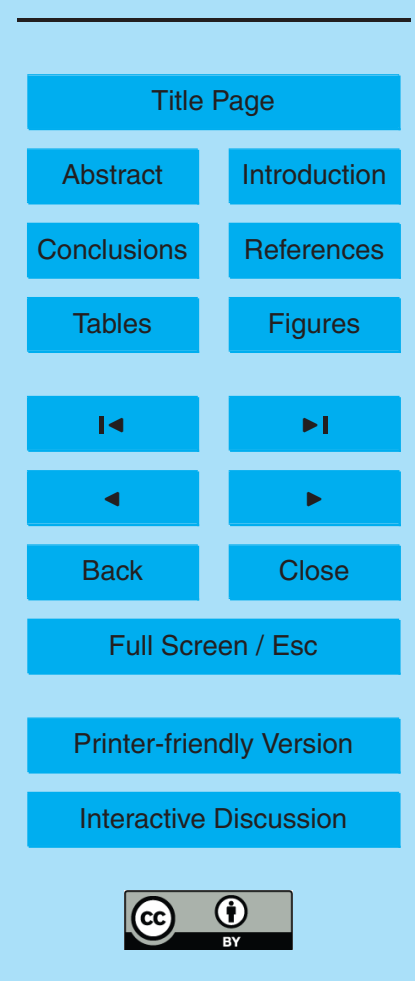


average vehicle of $6 \cdot 4 \cdot 10^{14} \mathrm{p}$. veh ${ }^{-1} \mathrm{~km}^{-1}$. Fitting the two separate modes yielded number emission factors of $4.4 \cdot 10^{14} \mathrm{p} . \mathrm{veh}^{-1} \mathrm{~km}^{-1}$ for the nucleation mode $\left(D_{g 0}=13 \mathrm{~nm}\right.$, $\left.\sigma_{g}=1.5\right)$ and $1.4 \cdot 10^{14} \mathrm{p}$. veh ${ }^{-1} \mathrm{~km}^{-1}$ for the soot particle mode $\left(D_{g 0}=82 \mathrm{~nm}, \sigma_{g}=1.9\right)$.

Our long-term average for the soot particle mode is not far from calculations based 5 on volatility tandem differential mobility analyzer measurements at Leipzig-Eiba (Rose et al., 2006). These authors associated non-volatile particles (at $300^{\circ} \mathrm{C}$ ) with primary emissions of soot, and found an emission factor of $1.5( \pm 0.4) \cdot 10^{14} \mathrm{p} . \mathrm{veh}^{-1} \mathrm{~km}^{-1}$ for the soot particle mode centered around $90 \mathrm{~nm}$. Rose et al. (2006) also derived a total emission factor of $4.9 \cdot 10^{14} \mathrm{p}$. veh ${ }^{-1} \mathrm{~km}^{-1}$, but this diverges more significantly from our results likely because their measurements were limited to short-term field campaigns.

The temperature dependency of the particle emissions can be pictured in terms of the particle size distribution as well: Figure 11 shows size distributions of $E$ that were segregated after different classes of ambient temperature. It can be seen that the nucleation mode shows an unequivocal trend along with temperature while the relative changes in the soot particle mode are smaller and do not follow the same trend with temperature. According to our results the number emissions in the nucleation mode may vary up to a factor of five, depending on ambient temperature. This finding has immediate consequences for the appropriate transport modelling of traffic emissions as well as the exposure assessment of residents to ultrafine aerosol particles.

As temperature was shown to play a crucial role in the number of traffic related particles, there is also an annual cycle in the particle emission factor, marked by a bandwidth of $4.8-7.8 \cdot 10^{14} \mathrm{p}$. veh ${ }^{-1} \mathrm{~km}^{-1}$ for summer and winter measurements, respectively. Since the major fraction of the particle volume emission factor $v$ is accounted for by the soot particle mode (Fig. 10), particle mass emissions vary comparatively little as a
ACPD

9, 3763-3809, 2009

Particle number emissions of motor traffic

S. Klose et al.

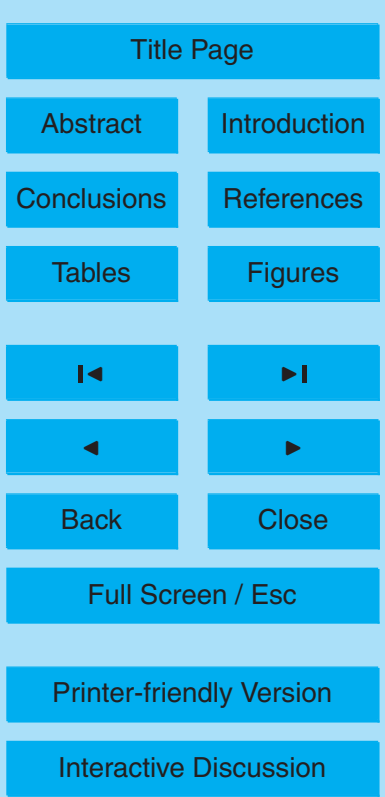


The aerosol at Leipzig-Eiba is influenced by mixed emissions of various vehicle types (passenger cars, transport vans, lorries, buses, motorbikes, etc.), and the emission factor will consequently represent an average over this entire fleet. We now attempt to 5 distinguish at least the effects of the two most representative vehicle classes, passenger car-like and lorry-like vehicles (cf. Sect. 2.3). In a simplified approach we assume that the total emission factor is a superposition of the emission factors of lorry-like $\left(E_{l}\right)$ and passenger-car like $\left(E_{p}\right)$ vehicles, weighted after their respective relative shares $n_{\text {I }}$ and $n_{p}$ :

$10 E=E_{l} \cdot n_{l}+E_{p} \cdot n_{p}$

As the fleet composition differs, for instance, between workdays and Sundays, it is possible to determine $E_{/}$and $E_{p}$ from Eq. (6) by multiple regression. The resulting total particle number emission factors were $5.4( \pm 2.1) \cdot 10^{14} \mathrm{p} \cdot \mathrm{veh}^{-1} \mathrm{~km}^{-1}$ for an average passenger car and $4.3( \pm 1.7) \cdot 10^{16} \mathrm{p} . \mathrm{veh}^{-1} \mathrm{~km}^{-1}$ for an average lorry-like vehicle. The 15 particle number emissions of lorry-like vehicles at the Leipzig-Eiba site were therefore determined to be approximately 80 times higher than an average passenger car. Our value is of a similar magnitude to results from a recent study in Switzerland by Imhof et al. (2005), who determined a ratio of 69 (cf. Table 2). Analogous calculations for the total particle volume yielded a ratio of about 7 between the emissions of lorry-like and 20 passenger car-like vehicles.

\subsection{Particulate vs. $\mathrm{NO}_{\mathrm{x}}$ emissions}

As both $\mathrm{NO}_{\mathrm{x}}$ and particles originate from traffic emissions, significant correlations between $\mathrm{NO}_{\mathrm{x}}$ and particle number are usually observed at roadside (Morawska et al., 1998; Charron and Harrison, 2003; Ketzel et al., 2003). This covariation reflects both

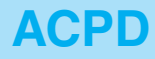

9, 3763-3809, 2009

\section{Particle number emissions of motor traffic}

S. Klose et al.

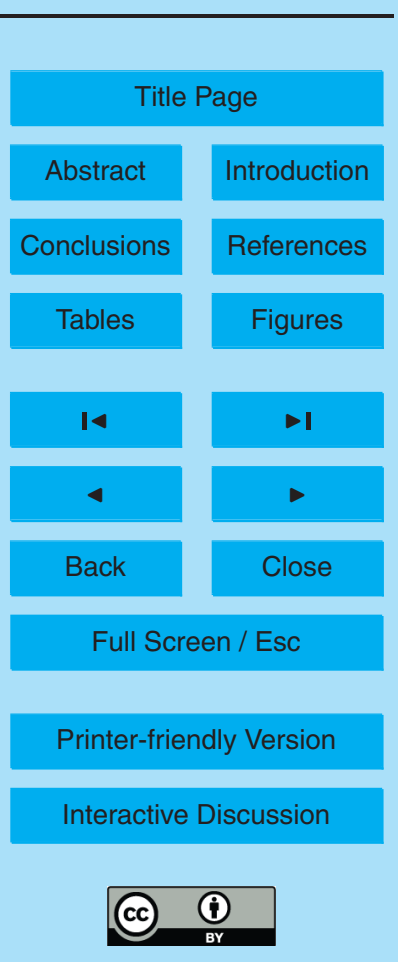


of the vehicular emissions. Some studies have also made use of known $\mathrm{NO}_{\mathrm{x}}$ emission factors in order to express particle emission factors relative to $\mathrm{NO}_{\mathrm{x}}$ (Janhäll and Hallquist, 2005).

Simultaneous measurements of $\mathrm{NO}_{\mathrm{x}}$ at Leipzig-Eiba and Leipzig-IfT were available 5 only for a limited period of 5 months (March to July 2005). Nevertheless, we were able to derive a mean ratio of $338 \mathrm{p}$. perpg NO from these data. This value is in qualitative agreement with calculations from similar traffic fleets in the street canyons of Copenhagen and Stockholm (260 p. perpg NO , Ketzel et al., 2003; 150-400 p. perpg NO Olivares et al., 2007).

10 Assuming that emitted $\mathrm{NO}_{\mathrm{x}}$ evolves analogous to particulate emissions with respect to their transport between the source and the receptor station, we calculated $\mathrm{NO}_{\mathrm{x}}$ emission factors with OSPM as well. Concentrating on workdays (08:00-18:00 LT) we calculated a mean $\mathrm{NO}_{\mathrm{x}}$ emission factor of $3.2( \pm 1.12) \mathrm{g} \mathrm{veh}^{-1} \mathrm{~km}^{-1}$. This value is, however, substantially higher than comparable observations in Copenhagen, where Ketzel et al. 15 (2003) obtained $1.3( \pm 0.2) \mathrm{g} \mathrm{veh}^{-1} \mathrm{~km}^{-1}$.

\subsection{Comparison with literature results}

Table 2 compares the results from this paper with published particle number emission factors. The comparison is focussed on studies that analysed slow-moving urban traffic in mainly densely built-up settings, such as street canyons, and on roads where the 20 traffic does not travel faster than $50 \mathrm{~km} \mathrm{~h}^{-1}$. For a more complete survey of literature number emission factors including also motorway traffic we refer to recent publications by the University of Birmingham (UK) (Jones and Harrison, 2006; Beddows and Harrison, 2008).

The Table shows that analyses specialised on slow-moving urban traffic are not plen25 tiful. The average particle emission factors are on the order of $10^{14} \mathrm{p} \mathrm{veh}^{-1} \mathrm{~km}^{-1}$, with HD traffic (corresponding to the "lorry-like vehicles" in this study) typically contributing between one and two orders of magnitude more than LD traffic (passenger car-like vehicles).

\section{Particle number emissions of motor traffic}

S. Klose et al.

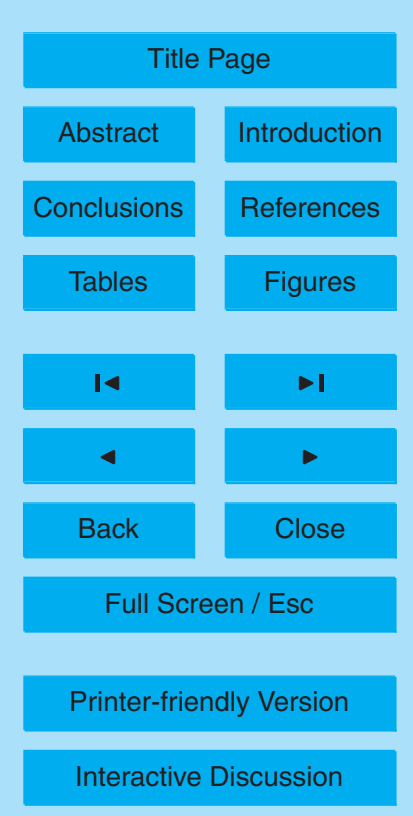


Our own results are representative for slow-moving urban traffic in a mainly residential area. According to HBEFA (2004) the share of diesel vehicles among passenger cars was $26 \%$ in Germany in 2004 , which we also take as representative of Leipzig. Meanwhile, the share of diesel vehicles among newly registered vehicles in Germany 5 has constantly increased, from 39.4\% in 2003 to 44.3\% in 2006 (KBA, 2004, 2006). Meanwhile, even greater changes are anticipated along with the introduction of diesel particulate filters since about 2006. In any case, such combined changes in fleet composition render each environmental emission factor study a "snapshot" of the conditions valid in the corresponding era.

10 Apart from possible differences in the fleet composition, the comparability of the studies compiled in Table 2 is drastically constrained by differences regarding the experimental and methodological methods. A first observation is that none of the studies available used the same lower size cut-off for their particle number measurement. Using the same size cut-off is a requirement for a direct comparability, since the peak of the emitted particle size distribution is around 10-15 nm (Fig. 10), which is unfortunately the range the lower size cut-off of most studies. Only a measurement down to $3 \mathrm{~nm}$ or lower can capture the full impact of traffic emissions, although we do know even less, practically nothing, on the possible adverse health effects of such small particles. While size distributions can, hypothetically be integrated over any desired size range, data on uniform size ranges are clearly not available (Table 2).

The studies mentioned in the Table further differ with respect to how dispersion was taken into account. The meteorological dilution was determined either by model simulations (OSPM (Ketzel et al., 2003), box model based on a particle number or mass balance equation, Morawska et al., 2005), or on the basis of assumed emission factors of $\mathrm{NO}_{\mathrm{x}}$ (Imhof et al., 2005). Further divergences may be caused by differences in vehicle types, the fraction of diesel vehicles, the year of observations, driving behaviour, measurement site characteristics, and, in a worst case, non-representative meteorological conditions.

For our own study we estimated the resulting uncertainties in $E$ by applying error

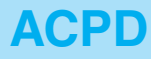

9, 3763-3809, 2009

\section{Particle number emissions of motor traffic}

S. Klose et al.

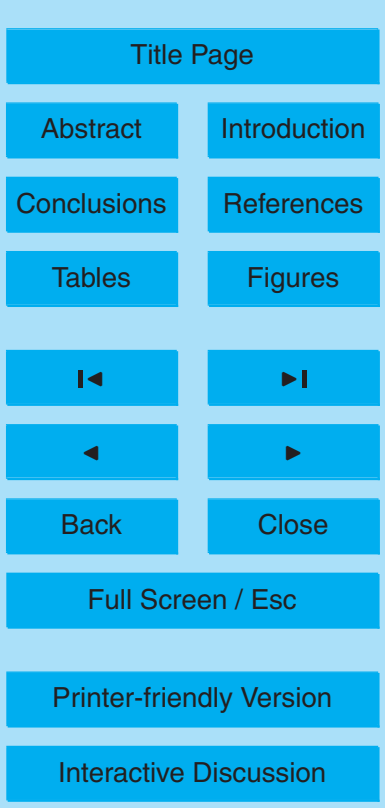


propagation. Each particle number concentration measurement is assumed to be accurate within $10 \%$, which is a value based on the evaluation method combined with instrumental experience. Uncertainties of the dilution factor $F$ were estimated by investigating its sensitivity to uncertainties in wind measurements and traffic counts. Po5 tential uncertainties caused by an oversimplification of the real topography in OSPM are hard to quantify and not even considered. Combining the different error sources yields a relative error in the final particle number emission factor of about $40 \%$.

For future studies it would also be desirable to describe the sub- $\mu \mathrm{m}$ number and mass emission factors as analytical functions describing the physical modes (i.e. the

10 nucleation and soot modes) which can be evaluated over arbitrary size ranges, and inputted directly into air quality models using aerosol dynamics.

\section{Conclusions}

The evaluation of a combined biennial data set of particle number size distributions $(4-800 \mathrm{~nm})$ collected inside a street canyon and in the urban background, and traffic 15 density confirmed a strong coupling of aerosol concentrations and traffic. Autocorrelation analysis revealed that the diurnal and weekly periodic behaviour of the particle concentrations are highly size-specific. The relative importance of the weekly periodic component suggested that the influence of photochemically produced particles dominates at particle diameters below $10 \mathrm{~nm}$ while nucleation from direct vehicle exhaust is 20 more relevant at nucleation mode particles above $10 \mathrm{~nm}$. A validation of forward simulations of the particle number increment at roadside with the dispersion model OSPM against measured time series demonstrated its sound applicability for the street canyon under study. Particle number emission factors $E$ obtained from an inverse application of OSPM modelling exposed several diurnal effects. High values during the period 03:00-06:00 LT were eventually interpreted as shortcomings in the model representation of the air flows in the street canyon but could ultimately not sufficiently be explained. During day-time, when the traffic volumes were high, the emission factors proved to be

\section{Particle number emissions of motor traffic}

S. Klose et al.

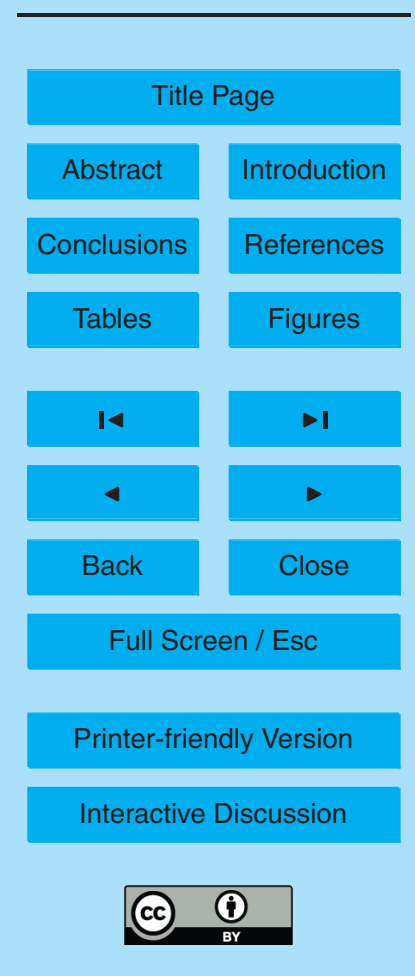


rather constant so that these values were aggregated as a final result. In the case of westerly wind directions we supposed an interfering influence of a neighbouring street on the estimated emission, so that this wind sector was treated separately.

The size spectrum of traffic-derived particles was essentially bimodal, with mode di5 ameters around 12 and $100 \mathrm{~nm}$. An essential result is that the emission factor was inversely dependent on ambient temperature. This effect was most pronounced for the nucleation mode $(<30 \mathrm{~nm})$ resulting in a typical rate of change $8 \cdot 10^{12} \mathrm{p} \cdot \mathrm{veh}^{-1} \mathrm{~km}^{-1}$ per ${ }^{\circ} \mathrm{C}$ in the size range $10-30 \mathrm{~nm}$. A separation of vehicle types according to vehicle length suggested that lorry-like vehicles emit about 80 times more particle number 10 than passenger car-like vehicles. Using nitrogen oxide $\left(\mathrm{NO}_{\mathrm{x}}\right)$ measurements, specific total particle number emissions of $338 \mathrm{p} .\left(\mathrm{pg} \mathrm{NO}_{\mathrm{x}}\right)^{-1}$ were inferred. It is important to note that all emission factors determined refer to the corresponding urban driving conditions (typical speed $30 \mathrm{~km} \mathrm{~h}^{-1}$, with stop-and-go traffic). A comparison with literature values yielded similar values in the same range of $10^{14} \mathrm{p} . \mathrm{veh}^{-1} \mathrm{~km}^{-1}$ for the average 15 fleets in different cities in Europe and Australia. Further solid conclusions are unfortunately hampered by intrinsic differences between all previous environmental emission factor studies regarding their experimental and computational methodology. Here, a more intense cross-validation between different research groups as well as the use of standardised experimental model techniques would be desirable.

20 The calculated traffic emission factors, considering particle number and size, are anticipated to provide useful input for future air quality and particle exposure modelling in densely populated urban areas. Since the total particulate vehicle emissions are anticipated to decrease over the years to come as a result of diesel particulate filters, a continuation of similar studies is recommended. Especially long-term observations 25 have the capacity to give evidence on the expected beneficial changes in terms of lower ambient concentrations of traffic-derived aerosol.

Acknowledgements. This work was supported by the German Federal Environment Agency (UBA) project UFOPLAN 204-42-204/03. Solar radiation measurements were kindly provided by J. Rehnert, Institute of Meteorology (LIM) at the University of Leipzig. Detlef Hinneburg

\section{Particle number emissions of motor traffic}

S. Klose et al.

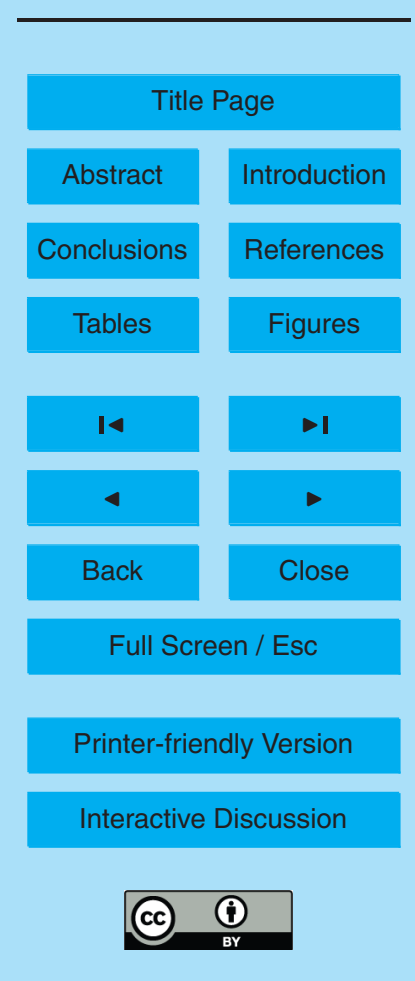


and Oswald Knoth are acknowledged for the supporting 3-D transport modelling in Sect. 5.2. The data evaluation for this paper was conducted within the European Integrated project on Aerosol Cloud Climate and Air Quality Interactions (EUCAARI), coordinated by the University of Helsinki, Finland.

\section{References}

Abdul-Khalek, I., Kittelson, D., and Brear, F.: Nanoparticle growth during dilution and cooling of diesel exhaust: experimental investigation and theoretical assessment, SAE Technical Paper Series, 2000-01-0515, 2000. 3780

Abu-Allaban, M., Gillies, J., Gertler, A., Clayton, R., and Proffitt, D.: Tailpipe, resuspended road 10 dust, and brake-wear emission factors from on-road vehicles, Atmos. Environ., 37, 52835293, 2003. 3765

Baltensperger, U., Streit, N., Weingartner, E., Nyeki, S., Prévôt, et al.: Urban and rural aerosol characterization of summer smog events during PIPAPO field campaign in Milan, Italy, J. Geophys. Res., 107(D22), 8193, doi:10.1029/2001D001292, 2002. 3766

15 Beddows, C. S. and Harrison, R. M.: Comparison of average particle number emission factors for heavy and light duty vehicles derived from rolling chassis dynamometer and field studies, Atmos. Environ., 42, 7954-7966, 2008. 3784

Berkowicz, R., Hertel, O., Larsen, S., Sørensen, N., and Nielsen, M.: Modelling traffic pollution in streets, Ministry of Environment and Energy, National Environmental Research Institute,

20 Denmark, 5283-5293, 1997. 3771

Birmili, W., Stratmann, F., and Wiedensohler, A.: Design of a DMA-based size spectrometer for a large particle size range and stable operation, J. Aerosol Sci., 30, 549-553, 1999. 3768

Birmili, W., Alaviippola, B., Hinneburg, D., Knoth, O., Tuch, T., Kleefeld-Borken, J., and Schacht, A.: Dispersion of traffic-related exhaust particles near the Berlin urban motorway: estimation of fleet emission factors, Atmos. Chem. Phys. Discuss., 8, 15537-15594, 2008, http://www.atmos-chem-phys-discuss.net/8/15537/2008/. 3772, 3779

Charron, A. and Harrison, R.: Primary particle formation from vehicle emissions during exhaust dilution in the roadside atmosphere, Atmos. Environ., 37, 4109-4119, 2003. 3774, 3783

Costabile, F., Birmili, W., Klose, S., Tuch, T., Wehner, B., Wiedensohler, A., Franck, U., König, K., and Sonntag, A.: Spatio-temporal variability and principal components of the particle

Particle number emissions of motor traffic

S. Klose et al.

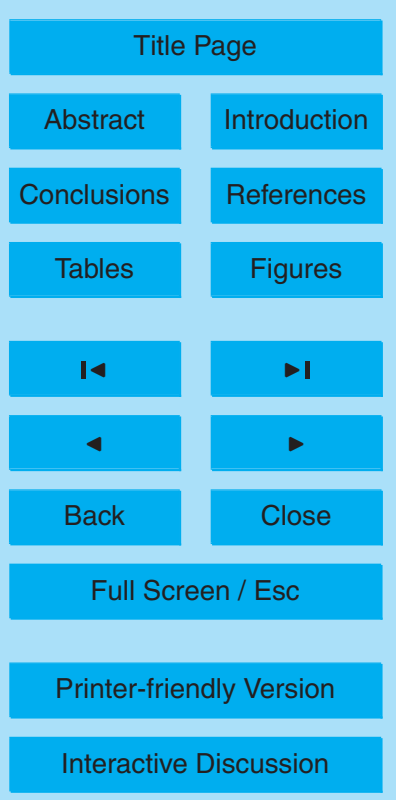

Interactive Discussion 
number size distribution in an urban atmosphere, Atmos. Chem. Phys. Discuss., 8, 1815518217, 2008, http://www.atmos-chem-phys-discuss.net/8/18155/2008/. 3773, 3777

Cohen, A. and Higgins, M.: Diesel exhaust: A critical analysis of emissions, exposure and health effects, Health Effects Institute, 251-292, 1995. 3765

5 Dahl, R.: Heavy traffic ahead: Car culture accelerates, Environ. Health Persp., 113, A238A245, 2005. 3765

Gehrig, R., Hill, M., Buchmann, B., Imhof, D., Weingartner, E., and Baltensperger, U.: Separate determination of $\mathrm{PM}_{10}$ emission factors of road traffic for tailpipe emissions and emissions from abrasion and resuspension processes, Int. J. Environ. Pollut., 22(3), 312-325, 2004. 3765

HBEFA: The handbook of emission factors for road transport, INFRAS, Bern, Switzerland, 2.1st edn., available at: http://www.hbefa.net/, 2004. 3785

Hoek, G., Goldbohm, S., Fischer, P., and van den Brandt, P.: Association between mortality and indicators of traffic-related air pollution in the Netherlands: a cohort study, Lancet, 360, 1203-1209, 2002. 3765

Horvath, H.: Atmospheric light absorption - a review, Atmos. Environ., 27A, 293-317, 1993. 3765

Hueglin, C., Buchmann, B., and Weber, R.: Long-term observation of real-world road traffic emission factors on a motorway in Switzerland, Atmos. Environ., 40, 3696-3709, 2006. 3774

Hussein, T., Hämeri, K., Aalto, P., Paatero, P., and Kulmala, M.: Modal structure and spatialtemporal variations of urban and suburban aerosols in Helsinki, Finland, Atmos. Environ., 39, 1655-1668, 2005.

Imhof, D., Weingartner, E., Ordónez, C., Gehrig, R., Hill, M., Buchmann, B., and Baltensperger, U.: Real-World Emission Factors of Fine and Ultrafine Aerosol Particles for Different Traffic Situations in Switzerland, Environ. Sci. Technol., 39, 8341-8350, 2005. 3783, 3785, 3794

Janhäll, S. and Hallquist, M.: A novel method for determination of size-resolved, submicrometer particle traffic emission factors, Environ. Sci. Technol., 39, 7609-7615, 2005. 3784

Jacobson, M. Z.: Strong radiative heating due to the mixing state of black carbon in atmospheric aerosols, Nature, 409(6821), 695-697, 2001. 3765

30 Jones, A. and Harrison, R.: Estimation of the emission factors of particle number and mass fraction from traffic at a site where mean vehicle speeds vary over short distances, Atmos. Environ., 40, 7125-7137, 2006. 3784, 3794

KBA: Jahresbericht des Kraftfahrt-Bundesamtes (Annual Rep. Federal Motor Transport Author-

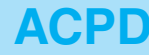

9, 3763-3809, 2009

\section{Particle number emissions of motor traffic}

S. Klose et al.

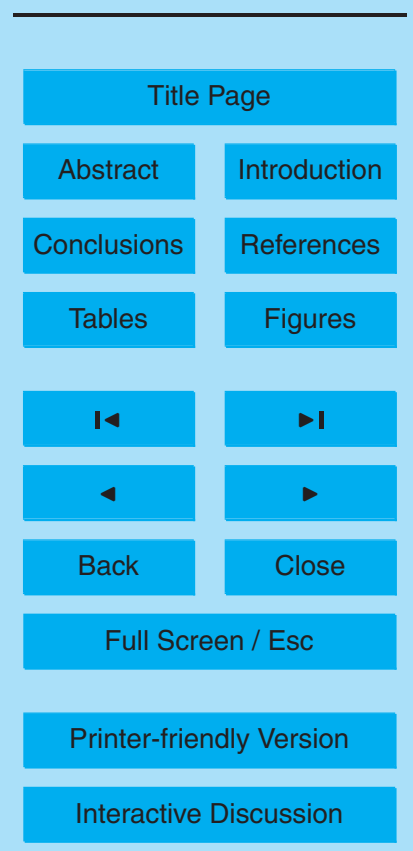


ity, Flensburg, Germany) 2003/2004, 24 pp., 2004. 3785

KBA: Jahresbericht des Kraftfahrt-Bundesamtes (Annual Rep. Federal Motor Transport Authority, Flensburg, Germany) 2006, 33 pp., 2006. 3785

Ketzel, M., Wåhlin, P., Berkowicz, R., and Palmgren, F.: Particle and trace gas emission factors 5 under urban driving conditions in Copenhagen based on street and roof-level observations, Atmos. Environ., 37, 2735-2749, 2003. 3771, 3774, 3777, 3778, 3783, 3784, 3785, 3794

Kittelson, D.: Engines and Nanoparticles: A Review, J. Aerosol Sci., 29, 575-588, 1998. 3765

Kittelson, D., Johnson, J., Watts, W., Wei, Q., Drayton, M., Paulsen, D., and Bukowiecki, N.: Diesel aerosol sampling in the atmosphere, SAE Technical Paper Series, 2000-01-2212, 2000. 3766

Kulmala, M., Vehkamäki, H., Petäjä, T., Dal Maso, M., Lauri, A., Kerminen, V. M., Birmili, W., and McMurry, P. H.: Formation and growth rates of ultrafine atmospheric particles: A review of observations, J. Aerosol Sci., 35, 143-176, 2004. 3773

Mathis, U., Mohr, M., and Forss, A.-M.: Comprehensive particle characterization of modern 15 gasoline and diesel passenger cars at low ambient temperatures, Atmos. Environ., 39, 107117, 2005. 3781

McClellan, R.: Health-effects of exposure to diesel exhaust particles, Annu. Rev. Pharmacolog., 27, 279-300, 1987. 3765

Molina, M. and Molina, L.: Critical Review: Megacities and Atmospheric Pollution, J. Air Waste Manage., 54, 644-680, 2004. 3765

Morawska, L., Thomas, S., Bofinger, N., Wainwright, D., and Neale, D.: Comprehensive characterization of aerosols in a subtropical urban atmosphere: Particle size distribution and correlation with gaseous pollutants, Atmos. Environ., 32, 2467-2478, 1998. 3783

Morawska, L., Jamriska, M., Thomas, S., et al.: Quantification of particle number emission 25 factors for motor vehicles from on-road measurements, Environ. Sci. Technol., 39, 91309139, 2005. 3785, 3794

Ntziachristos, L., Mamakos, A., Samaras, Z., Mathis, U., Mohr, M., et al.: Overview of the european Particulates project on the characterization of exhaust particulate emissions from road vehicles: Results for light-duty vehicles, SAE transactions, 113, 1354-1373, 2004. 3766 30 Oke, T.: Street design and urban canopy layer climate, Energ. Buildings.,11, 103-113, ,1998. 3766

Olivares, G., Johansson, C., Ström, J., and Hanson, H.: The role of ambient temperature for particle number concentrations in a street canyon, Atmos. Environ., 41, 2145-2155, 2007.

\section{Particle number emissions of motor traffic}

S. Klose et al.

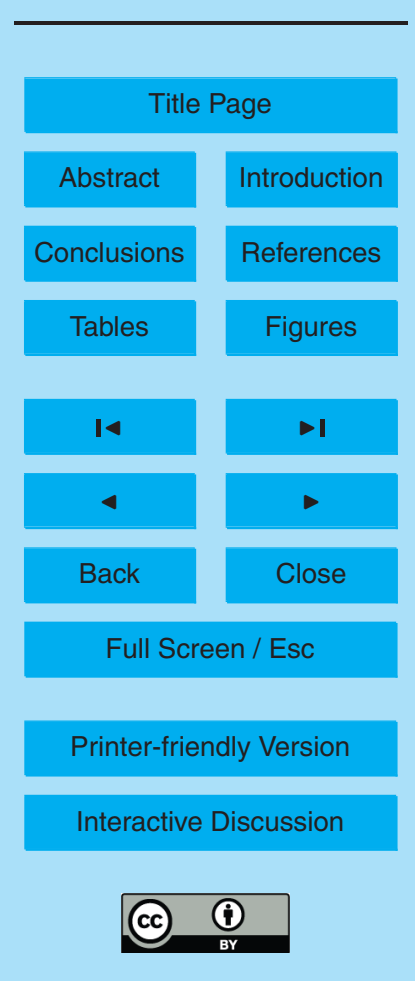


3781,3784

Palmgren, F., Berkowicz, R., Ziv, A., and Hertel, O.: Actual car fleet emissions estimated from urban air quality measurements and street pollution models, Sci. Total Environ., 235, 101109, 1999. 3771

5 Palmgren, F., Wåhlin, P., Berkowicz, R., Ketzel, M., Illerup, J., Nielsen, M., Winther, M., Glasius, M., and Jensen, B.: Aerosol in Danish Air (AIDA), Mid-term report 2001-2002, National Environmental Research Institute, Roskilde, Denmark, NERI Technical Report No. 460, 2003. 3781

Pohjola, M., Pirjola, L., Kukkonen, J., and Kulmala, M.: Modelling of the influence of aerosol processes for the dispersion of vehicular exhaust plumes in street environment, Atmos. Environ. 37, 339-351, 2003. 3772

Rose, D., Wehner, B., Ketzel, M., Engler, C., Voigtländer, J., Tuch, T., and Wiedensohler, A.: Atmospheric number size distributions of soot particles and estimation of emission factors, Atmos. Chem. Phys., 6, 1021-1031, 2006, http://www.atmos-chem-phys.net/6/1021/2006/. 3776, 3782

Schäfer, K., Emeis, S., Hoffmann, H., and Jahn, C.: Influence of mixing layer height upon air pollution in urban and sub-urban areas, Meteorol. Z., 15, 647-658, 2006. 3773

Seaton, A., MacNee, W., Donaldson, K., and Godden, D.: Particulate Air Pollution and Acute Health Effects, Lancet, 345, 176-178, 1995. 3765

20 Shi, J. and Harrison, R.: Investigation of ultrafine particle formation during diesel exhaust dilution, Environ. Sci. Technol., 33(21), 3730-3736, 1999. 3780

United Nations: World Urbanization Prospects: The 2007 Revision, Geneva, available at: http://www.un.org/esa/population/publications/wup2007/2007WUP_ExecSum_web. pdf, 2007. 3765

Vardoulakis, S., Fisher, B., Pericleous, K., and Gonzalez-Flesca, N.: Modelling air quality in street canyons: a review, Atmos. Environ., 37, 155-182, 2003. 3766

Voigtländer, J., Tuch, T., Birmili, W., and Wiedensohler, A.: Correlation between traffic density and particle size distribution in a street canyon and the dependence on wind direction, Atmos. Chem. Phys., 6, 4275-4286, 2006,

30 http://www.atmos-chem-phys.net/6/4275/2006/. 3767

Voit, H.: Press release no. 237, Federal Statistical Office of Germany, available at: http://www.destatis.de/jetspeed/portal/cms/Sites/destatis/Internet/DE/Presse/pm/2005/ 05/PD05_237__129,templateld=renderPrint.psml, 30 May 2005. 3765

\section{Particle number emissions of motor traffic}

S. Klose et al.

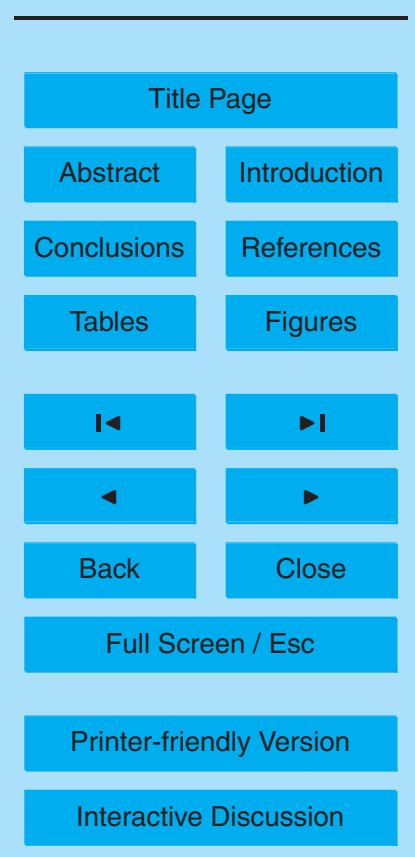


Wehner, B. and Wiedensohler, A.: Long term measurements of submicrometer urban aerosols: statistical analysis for correlations with meteorological conditions and trace gases, Atmos. Chem. Phys., 3, 867-879, 2003,

http://www.atmos-chem-phys.net/3/867/2003/. 3768

5 Zhang, K. M., Wexler, A. S., Zhu, Y., Hinds, W. C., and Sioutas, C.: Evolution of particle number distribution near roadways - Part II: the "Road-to-Ambient" process, Atmos. Environ., 38, $6655-6665,2004.3766,3772$

\section{ACPD}

\section{9, 3763-3809, 2009}

\section{Particle number emissions of motor traffic}

S. Klose et al.

\section{Title Page}

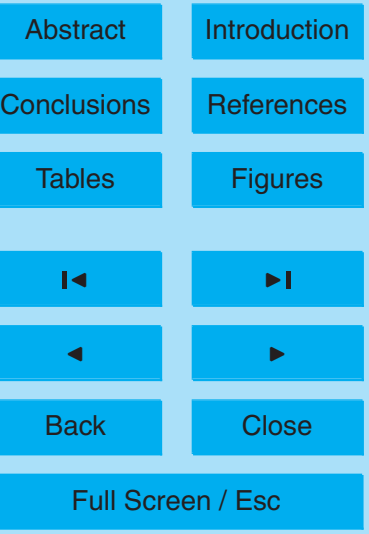

Printer-friendly Version

Interactive Discussion 


\section{ACPD}

\section{9, 3763-3809, 2009}

Table 1. Mean diurnal cycle of the modal parameters of three lognormal modes on workdays. The parameters include particles number concentration $N$ in $\mathrm{cm}^{-3}$, geometric mean diameter $D_{g 0}$ in $\mathrm{nm}$, and the spread parameter $\sigma$.

\begin{tabular}{|c|c|c|c|c|c|c|c|c|c|}
\hline \multirow[t]{2}{*}{ Period } & \multicolumn{3}{|c|}{$\begin{array}{c}\text { Nucleation mode } \\
\sigma_{g}=1.7\end{array}$} & \multicolumn{3}{|c|}{$\begin{array}{c}\text { Aitken mode } \\
\sigma_{g}=1.58\end{array}$} & \multicolumn{3}{|c|}{$\begin{array}{l}\text { Accumulation mode } \\
\sigma_{g}=1.59\end{array}$} \\
\hline & $D_{g 0}$ & $N_{\text {Eiba }}$ & $N_{\text {IfT }}$ & $D_{g 0}$ & $N_{\text {Eiba }}$ & $N_{\text {IfT }}$ & $D_{g 0}$ & $N_{\text {Eiba }}$ & $N_{\text {IfT }}$ \\
\hline 00:00-02:00 & 21 & 6950 & 4690 & 68 & 4540 & 3910 & 173 & 2110 & 1540 \\
\hline 02:00-04:00 & 22 & 6200 & 4510 & 75 & 4000 & 3700 & 209 & 1470 & 1480 \\
\hline 04:00-06:00 & 22 & 8740 & 5610 & 76 & 4210 & 3250 & 185 & 2040 & 1060 \\
\hline 06:00-08:00 & 18 & 19610 & 7280 & 70 & 6410 & 5070 & 175 & 2430 & 1620 \\
\hline 08:00-10:00 & 18 & 21730 & 7100 & 70 & 7220 & 5120 & 175 & 2610 & 1630 \\
\hline 10:00-12:00 & 15 & 20660 & 6170 & 66 & 7300 & 4620 & 175 & 2650 & 1480 \\
\hline 12:00-14:00 & 14 & 21860 & 7100 & 66 & 6730 & 3980 & 173 & 2580 & 1390 \\
\hline 14:00-16:00 & 17 & 21950 & 7870 & 68 & 6680 & 3710 & 176 & 2600 & 1350 \\
\hline 16:00-18:00 & 17 & 18560 & 7520 & 68 & 6830 & 3700 & 172 & 2650 & 1330 \\
\hline 18:00-20:00 & 18 & 14810 & 6490 & 66 & 6680 & 4040 & 170 & 2650 & 1550 \\
\hline 20:00-22:00 & 20 & 12360 & 6310 & 70 & 6400 & 4190 & 175 & 2550 & 1430 \\
\hline 22:00-24:00 & 21 & 9950 & 5460 & 70 & 5490 & 4260 & 175 & 2280 & 1510 \\
\hline
\end{tabular}

Particle number emissions of motor traffic

S. Klose et al.

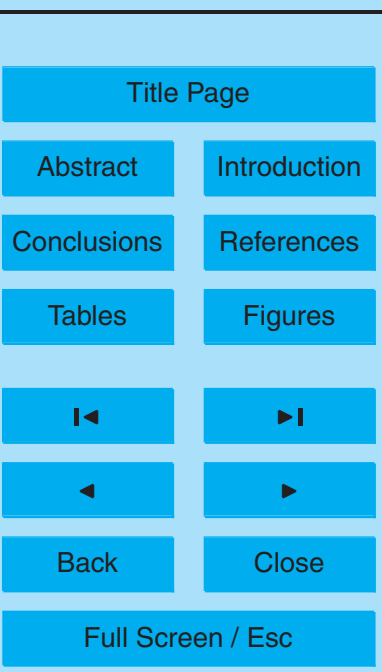

Printer-friendly Version

Interactive Discussion 


\section{ACPD}

9, 3763-3809, 2009

Table 2. Compilation of particle emission factors determined from on-road studies; HD: heavy duty, LD: light duty.

\begin{tabular}{|c|c|c|c|c|c|}
\hline Author & $\begin{array}{l}\text { Measurement } \\
\text { site }\end{array}$ & $\begin{array}{l}\text { Fleet } \\
\text { characte- } \\
\text { ristics }\end{array}$ & $\begin{array}{l}\text { Vehicle } \\
\text { speed } \\
\text { in } \mathrm{km} \mathrm{h}^{-1}\end{array}$ & $\begin{array}{l}\text { Size range } \\
\text { in } \mathrm{nm}\end{array}$ & $\begin{array}{l}\text { Emission factor } \\
\text { in } 10^{14} \mathrm{p} . \mathrm{veh}^{-1} \mathrm{~km}^{-1}\end{array}$ \\
\hline Ketzel et al. (2003) & street canyon & $\begin{array}{l}\text { mixed, } \\
\text { HD: } 6-8 \% \text {, } \\
7 \% \text { of LD } \\
\text { are diesel }\end{array}$ & $40-50$ & $10-700$ & $2.8( \pm 0.5)$ \\
\hline Morawska et al. (2005) & street canyon & $\begin{array}{l}\text { petrol } \\
\text { diesel }\end{array}$ & $\begin{array}{l}\text { stop-start } \\
\text { stop-start }\end{array}$ & $\begin{array}{l}18-880 \\
18-880\end{array}$ & $\begin{array}{l}0.28( \pm 0.057) \\
2.04( \pm 0.24)\end{array}$ \\
\hline Imhof et al. (2005) & urban road & $\begin{array}{l}\text { LD } \\
\text { HD }\end{array}$ & $\begin{array}{l}50 \\
50\end{array}$ & $\begin{array}{l}>7 \\
>7\end{array}$ & $\begin{array}{l}0.8 \\
55\end{array}$ \\
\hline Jones and Harrison (2006) & street canyon & $\begin{array}{l}\text { LD } \\
\text { HD }\end{array}$ & $\begin{array}{l}<50 \\
<50\end{array}$ & $\begin{array}{l}11-450 \\
11-450\end{array}$ & $\begin{array}{l}0.122 \\
6.36\end{array}$ \\
\hline \multirow[t]{3}{*}{ present work } & street canyon & $\begin{array}{l}\text { mixed, } \\
4 \% \mathrm{HD}\end{array}$ & 30, stop-start & $4-800$ & $\begin{array}{l}\text { annual mean: } 6.4( \pm 2.4) \\
\text { summer: } 4.8( \pm 1.8) \\
\text { winter: } 7.8( \pm 2.9)\end{array}$ \\
\hline & & LD & 30, stop-start & $4-800$ & $5.4( \pm 2.1)$ \\
\hline & & HD & 30, stop-start & $4-800$ & $430( \pm 170)$ \\
\hline
\end{tabular}

\section{Particle number emissions of motor traffic}

S. Klose et al.

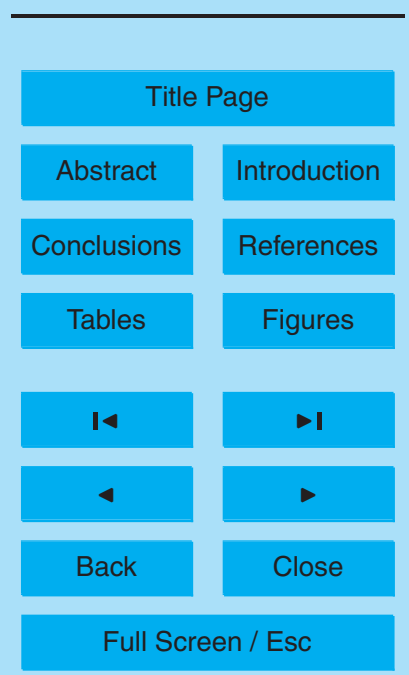

Printer-friendly Version

Interactive Discussion 


\section{ACPD}

9, 3763-3809, 2009

(a)

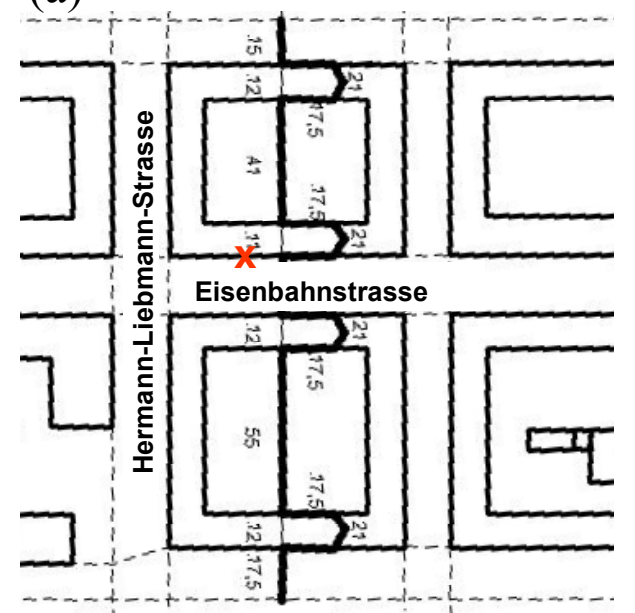

(b)

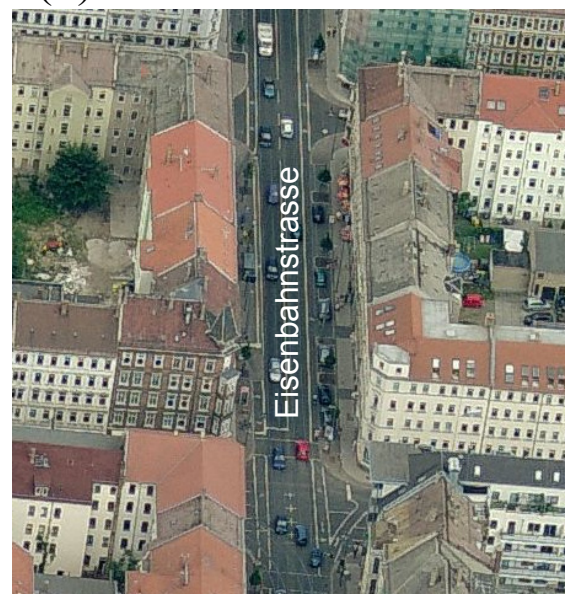

Fig. 1. (a) Plan view of the street canyon Leipzig-Eisenbahnstrasse and its surroundings (north on top). The red cross marks the location of the sampling point; (b) Bird's eye view from the west (Microsoft Virtual Earth 2007).

\section{Particle number} emissions of motor traffic

S. Klose et al.

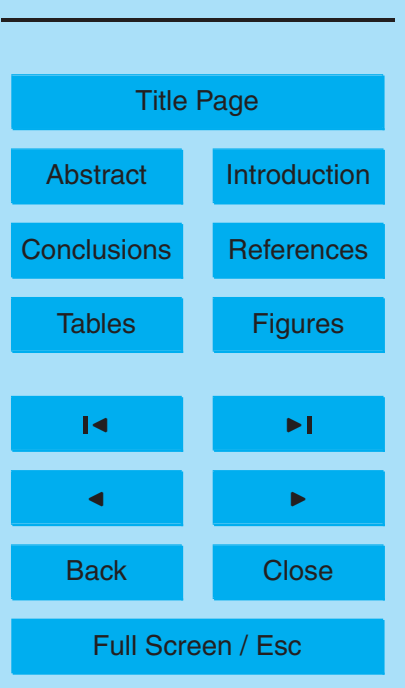

Printer-friendly Version

Interactive Discussion 


\section{ACPD}

\section{9, 3763-3809, 2009}

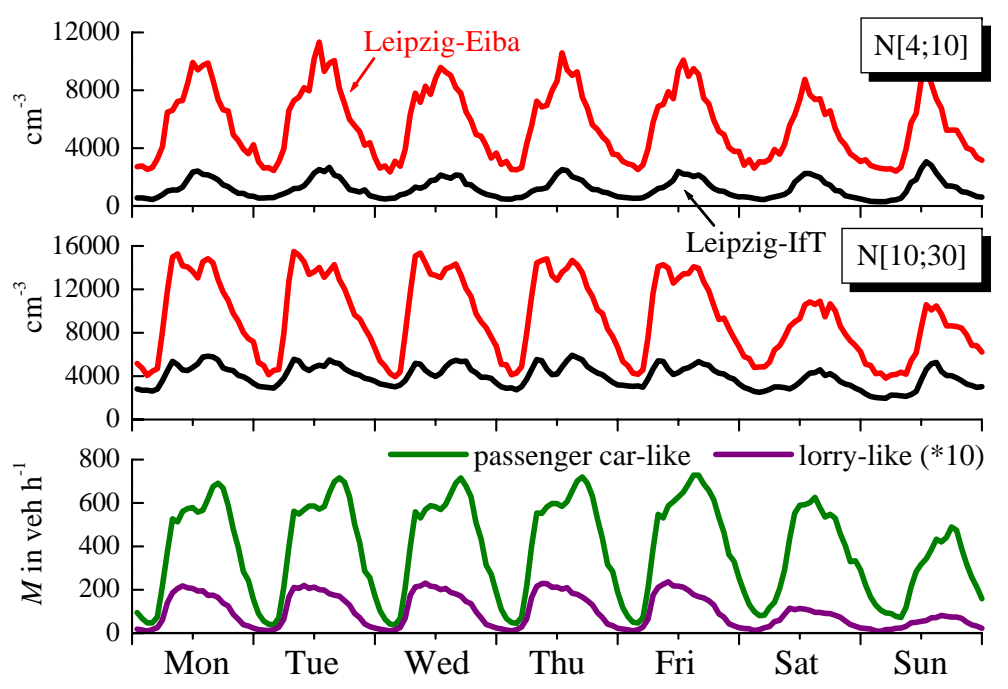

\section{Particle number emissions of motor traffic}

S. Klose et al.

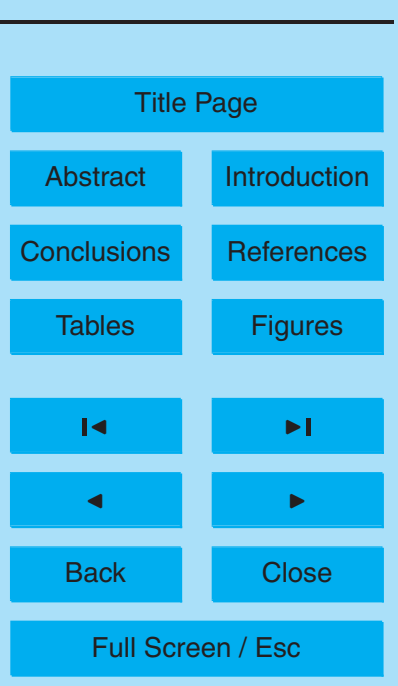

Printer-friendly Version

Fig. 2a. Weekly average cycle of particle number concentration $N_{[4 ; 10]}$ and $N_{[10 ; 30]}$ in the street canyon (Leipzig-Eiba) and the urban background site (Leipzig-IfT). The cycle of traffic density in the street canyon is added for illustration. Data coverage: 2005 and 2006.

Interactive Discussion 


\section{ACPD}

\section{9, 3763-3809, 2009}

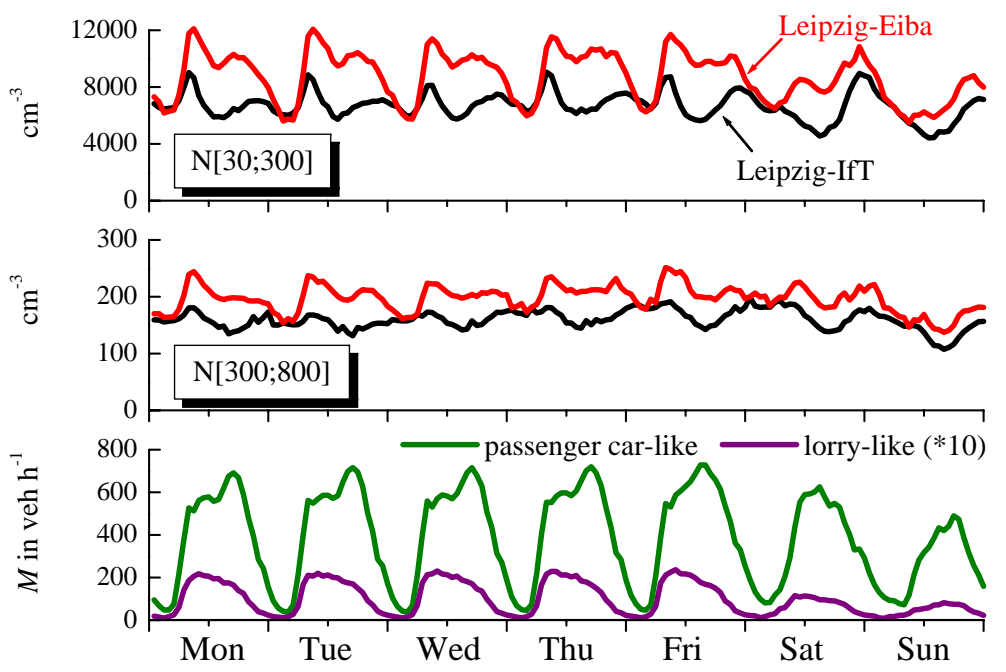

\section{Particle number emissions of motor traffic}

S. Klose et al.

Title Page

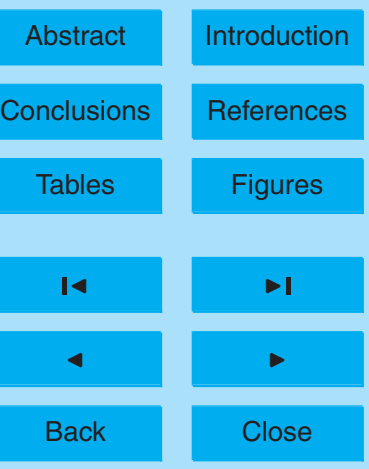

Full Screen / Esc

Printer-friendly Version

Interactive Discussion 


\section{ACPD}

\section{9, 3763-3809, 2009}

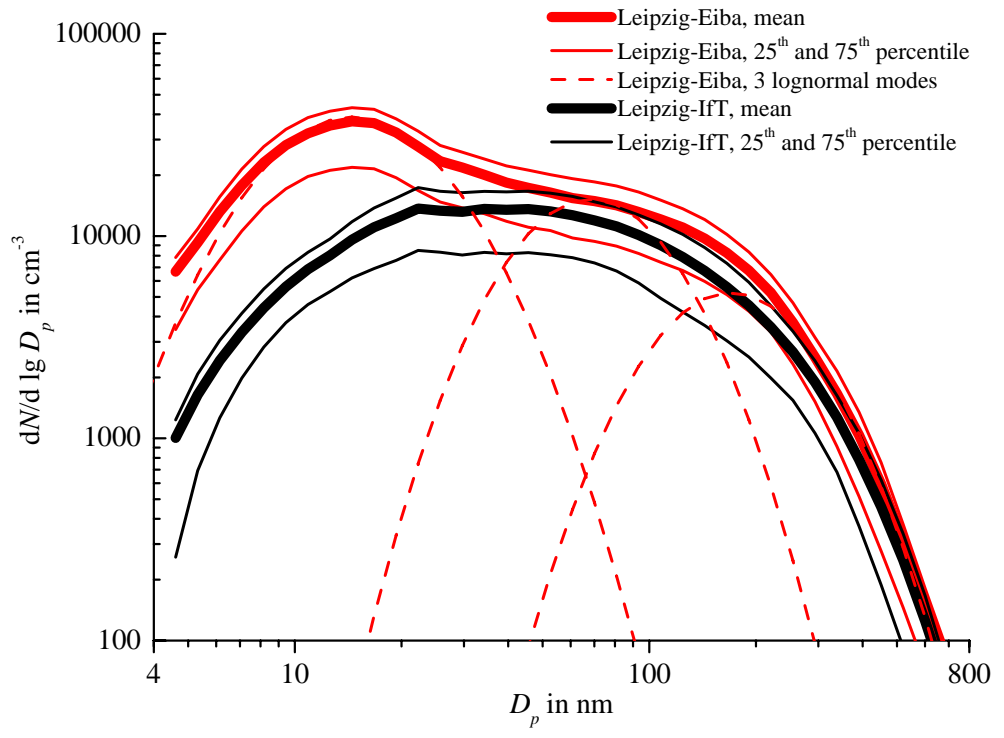

\section{Particle number emissions of motor traffic}

S. Klose et al.

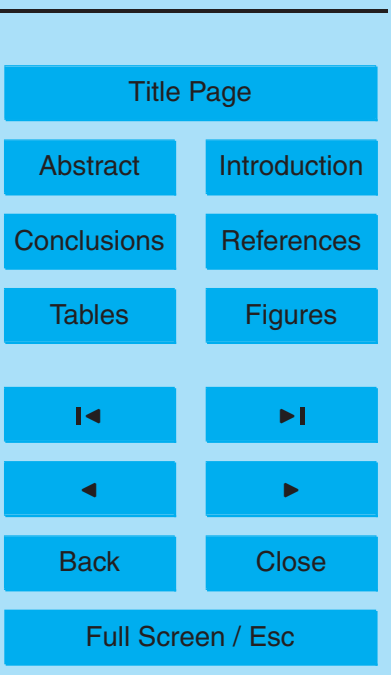

Fig. 3. Particle number size distributions in the street canyon (Leipzig-Eiba) and the urban background site (Leipzig-IfT) during the weekday morning rush hour (Mon-Fri, 08:00-09:00 LT). Data coverage: 2005 and 2006. Three lognormal modes were fitted for illustration.
Printer-friendly Version

Interactive Discussion

\section{Full Screen / Esc}

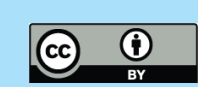




\section{ACPD}

9, 3763-3809, 2009

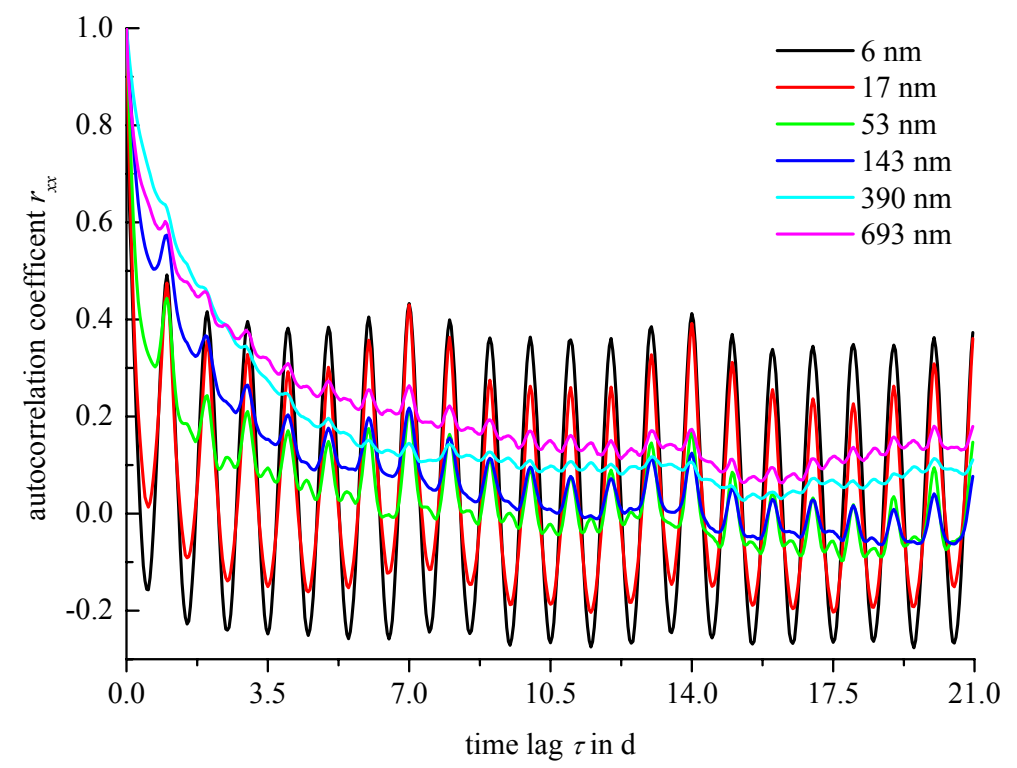

\section{Particle number} emissions of motor traffic

S. Klose et al.

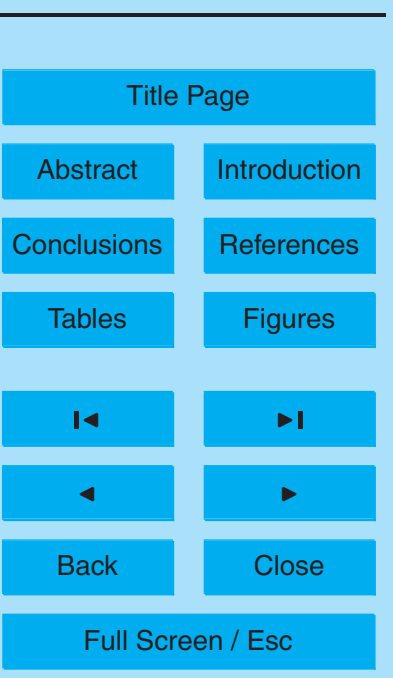

Printer-friendly Version

Fig. 4. Autocorrelation coefficient $r_{x x}$ of particle number concentration as a function of the lag time $\tau$ for selected particle diameters. 


\section{ACPD}

9, 3763-3809, 2009

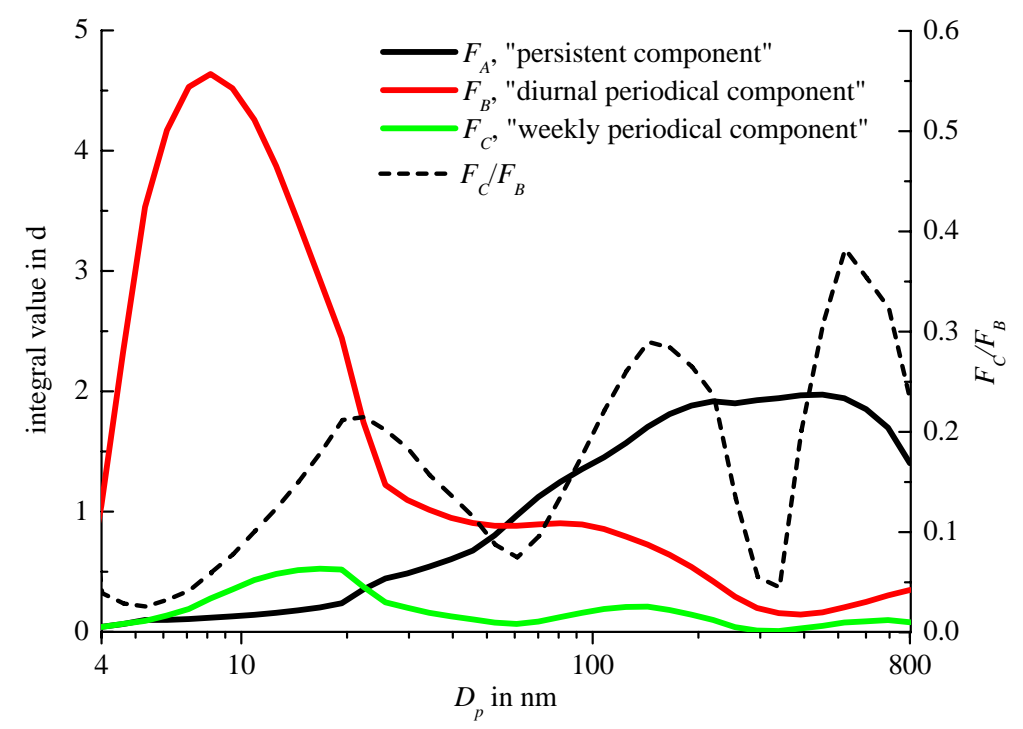

\section{Particle number emissions of motor traffic}

S. Klose et al.

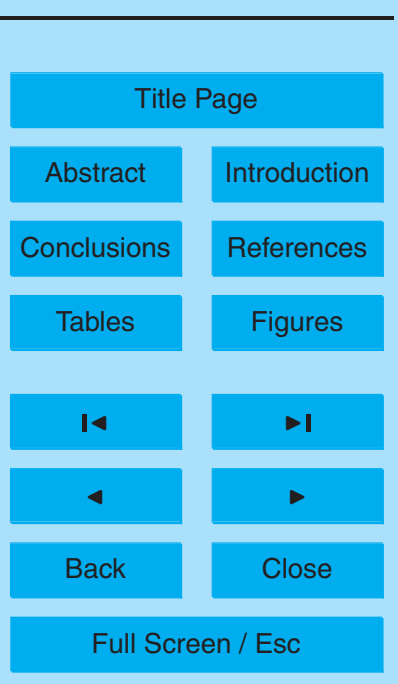

Printer-friendly Version

Fig. 5. Integral values of the individual components $F_{A}, F_{B}$, and $F_{C}$ of the autocorrelation function as a function of particle diameter. The different components quantify the different periodicities present in the number concentration data.

Interactive Discussion 


\section{ACPD}

9, 3763-3809, 2009

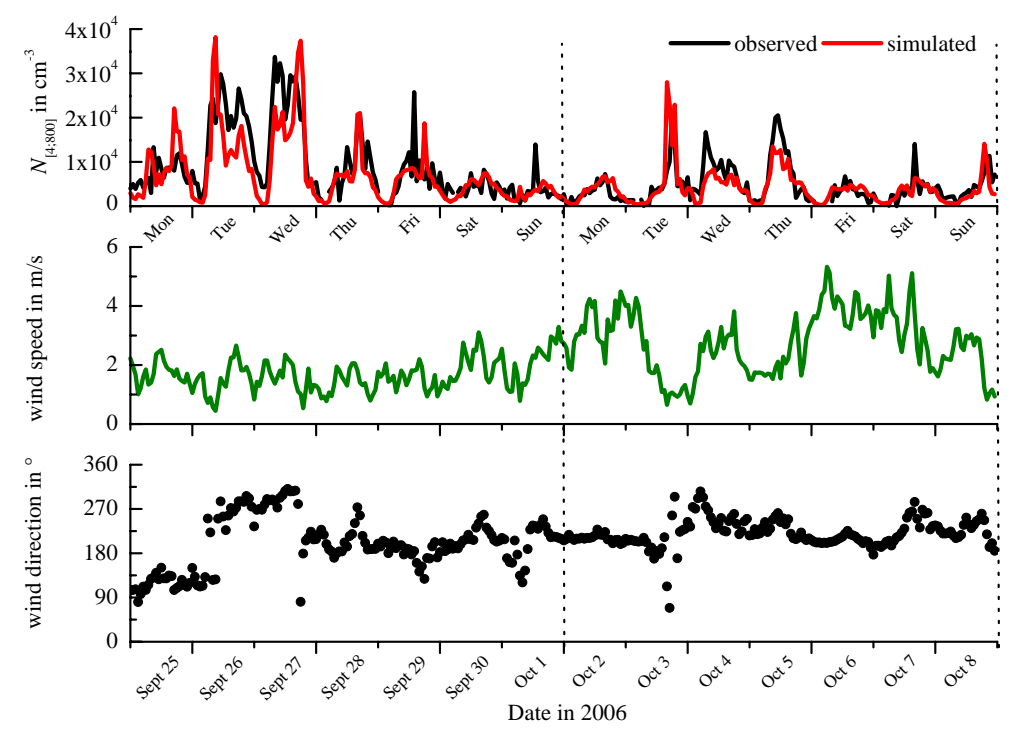

\section{Particle number} emissions of motor traffic

S. Klose et al.

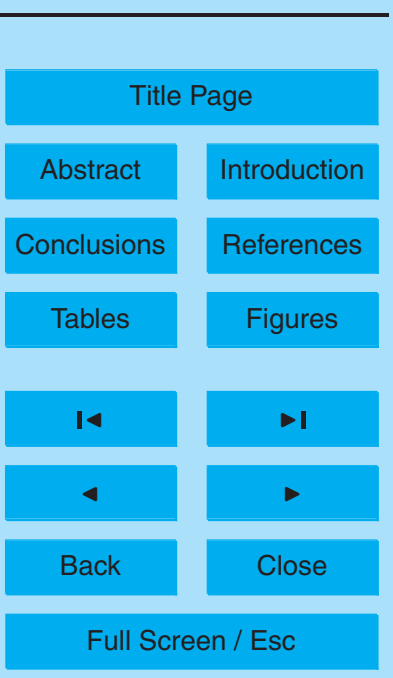

Printer-friendly Version

Fig. 6a. Time series of the particle number concentration increment in the street canyon (diameter range: $4-800 \mathrm{~nm}$ ), simulations and observations. Local wind speed and wind direction are added for illustration.

Interactive Discussion 


\section{ACPD}

9, 3763-3809, 2009

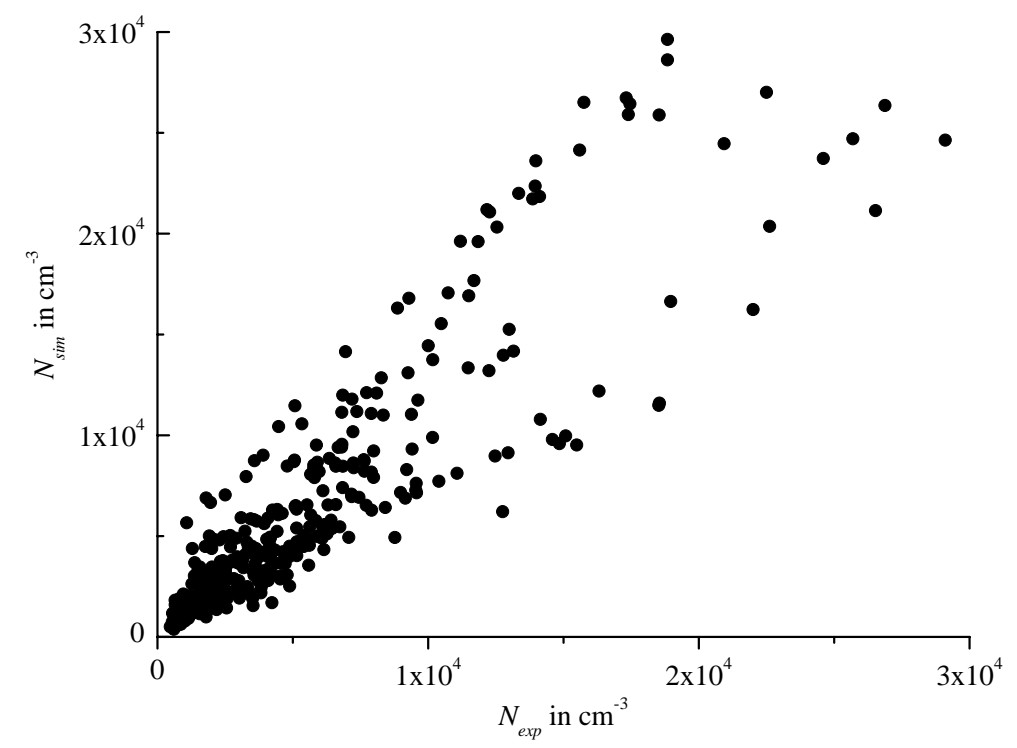

\section{Particle number} emissions of motor traffic

S. Klose et al.

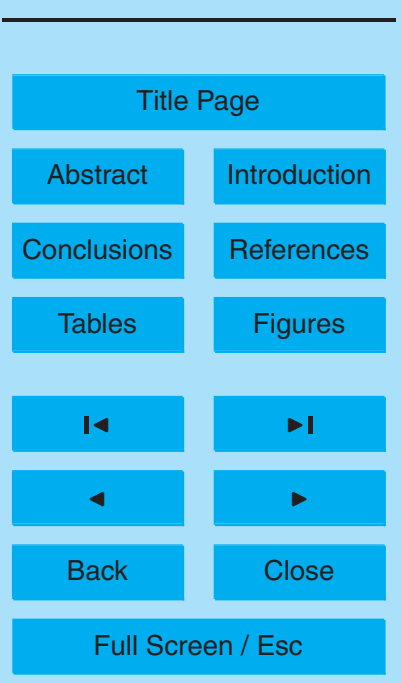

Printer-friendly Version

Interactive Discussion 


\section{ACPD}

9, 3763-3809, 2009

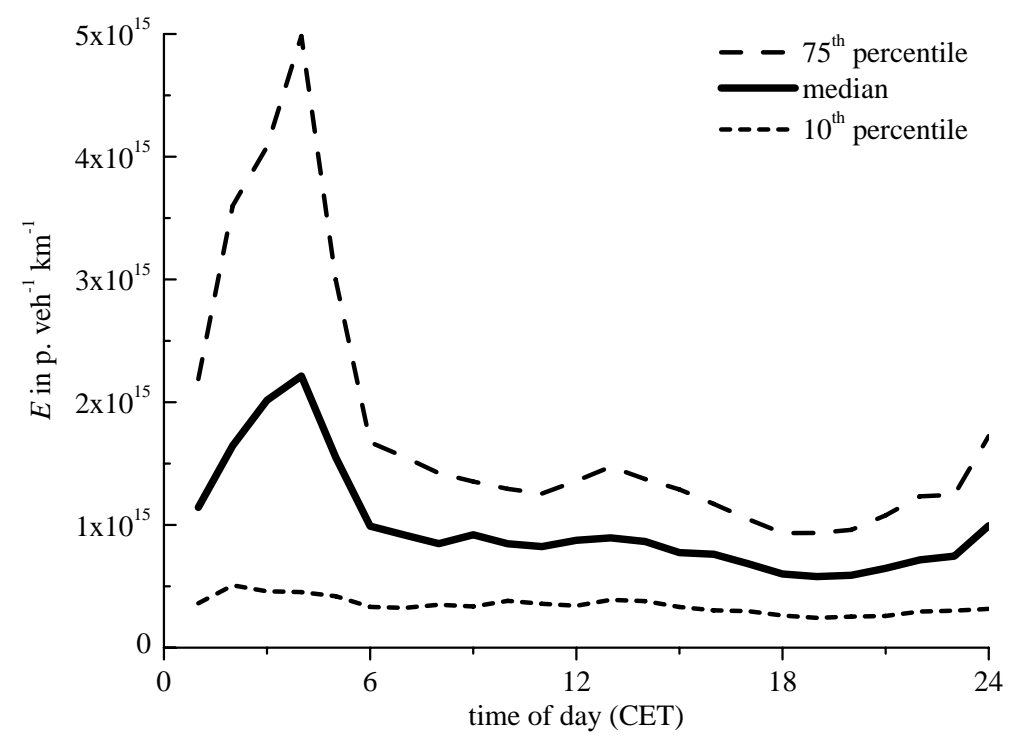

\section{Particle number emissions of motor traffic \\ S. Klose et al.}

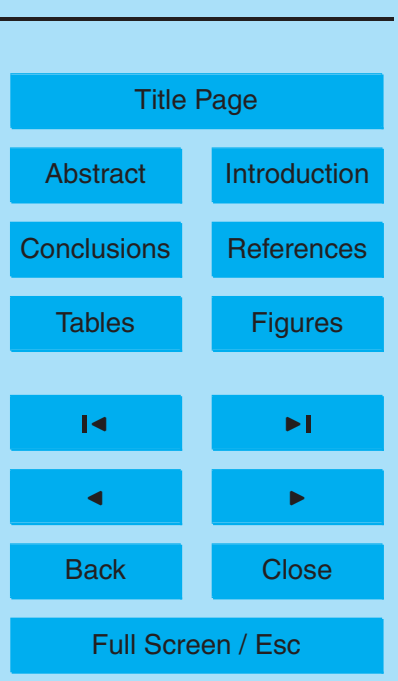

Printer-friendly Version

Fig. 7. Diurnal cycle of the particle number emission factor $\left(D_{p}\right.$ range $\left.4-800 \mathrm{~nm}\right)$ in the LeipzigEisenbahnstrasse street canyon. Data coverage: 2005 and 2006.

Interactive Discussion 


\section{ACPD}

9, 3763-3809, 2009

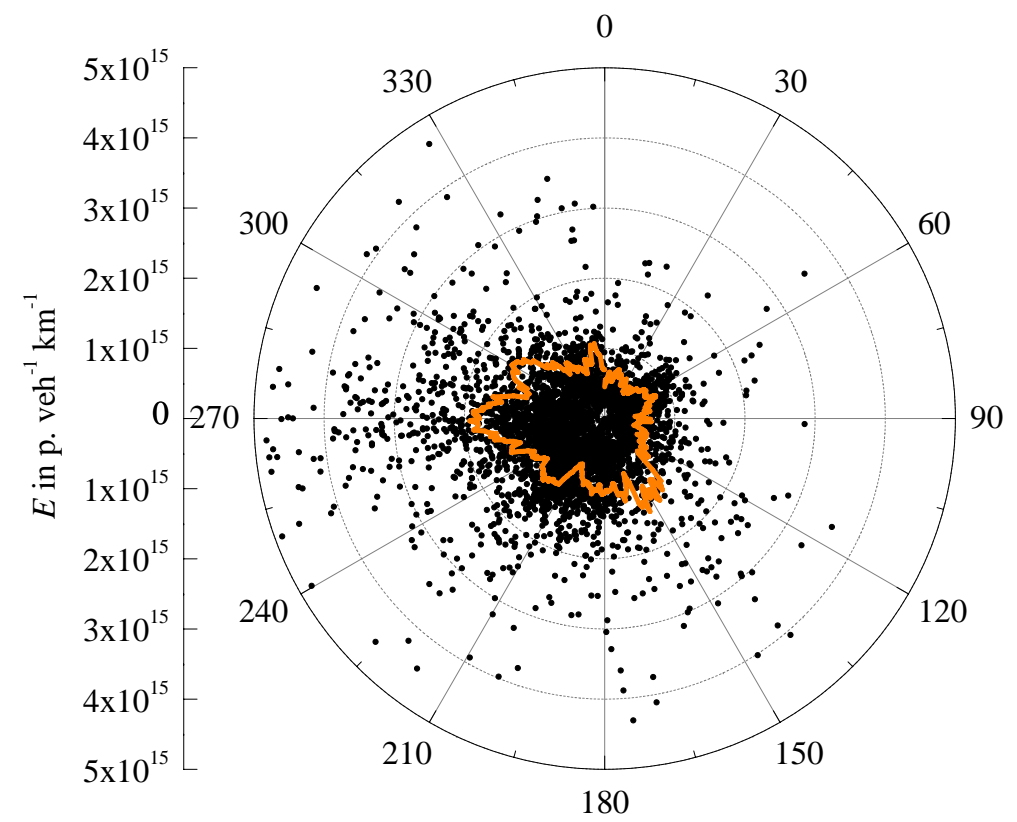

\section{Particle number emissions of motor traffic}

S. Klose et al.

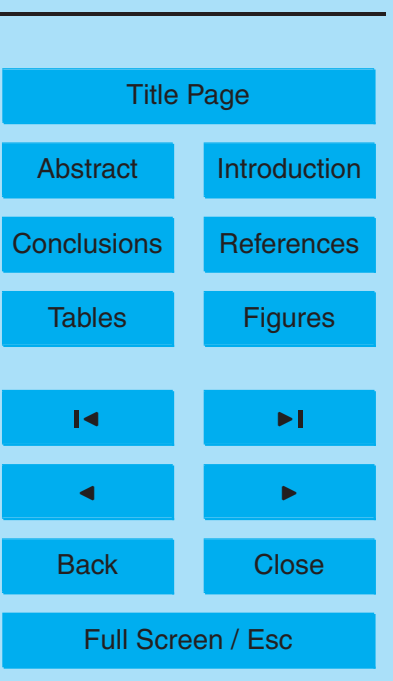

Fig. 8. The particle number emission factor $\left(D_{p}\right.$ range $\left.4-800 \mathrm{~nm}\right)$ as a function of the roof-top wind direction. Data coverage: 2005 and 2006, 08:00-18:00 LT. 


\section{ACPD}

9, 3763-3809, 2009

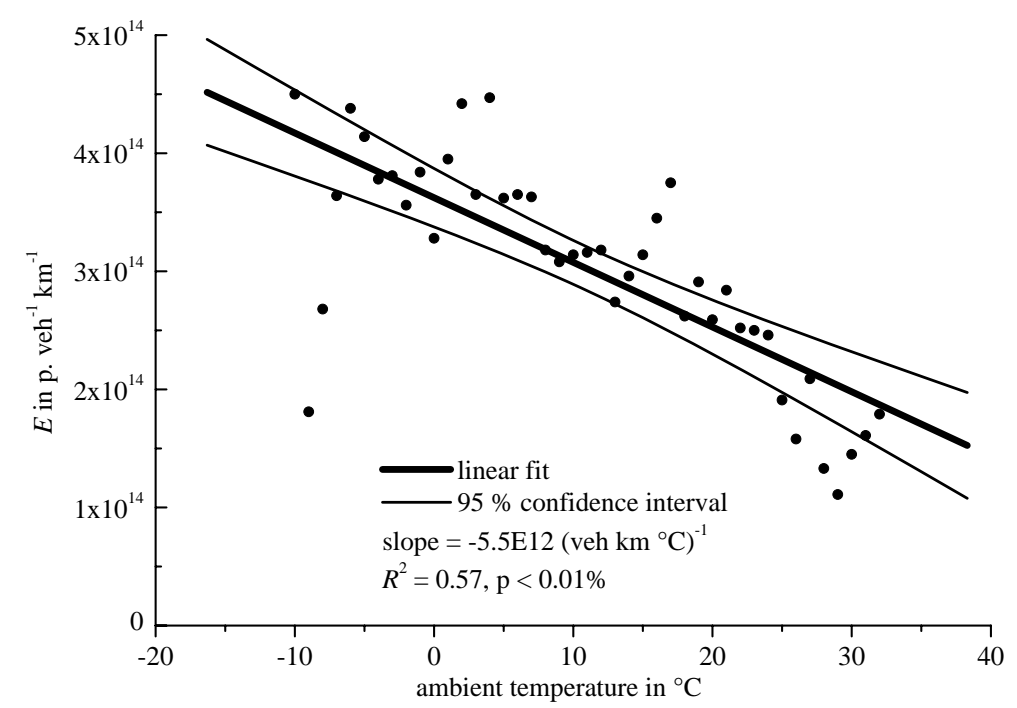

\section{Particle number} emissions of motor traffic

S. Klose et al.

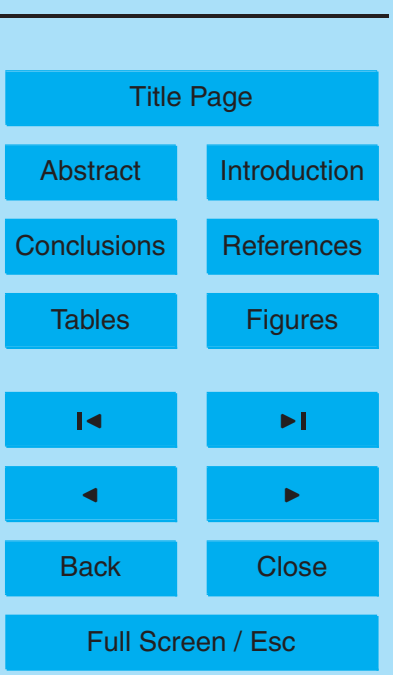

Printer-friendly Version

Fig. 9a. Particle number emission factor $\left(D_{p}\right.$ range $\left.4-10 \mathrm{~nm}\right)$ as a function of ambient temperature. Data coverage: 2005 and 2006, 06:00-10:00 LT.

Full Screen / Esc

Interactive Discussion 


\section{ACPD}

\section{9, 3763-3809, 2009}

\section{Particle number}

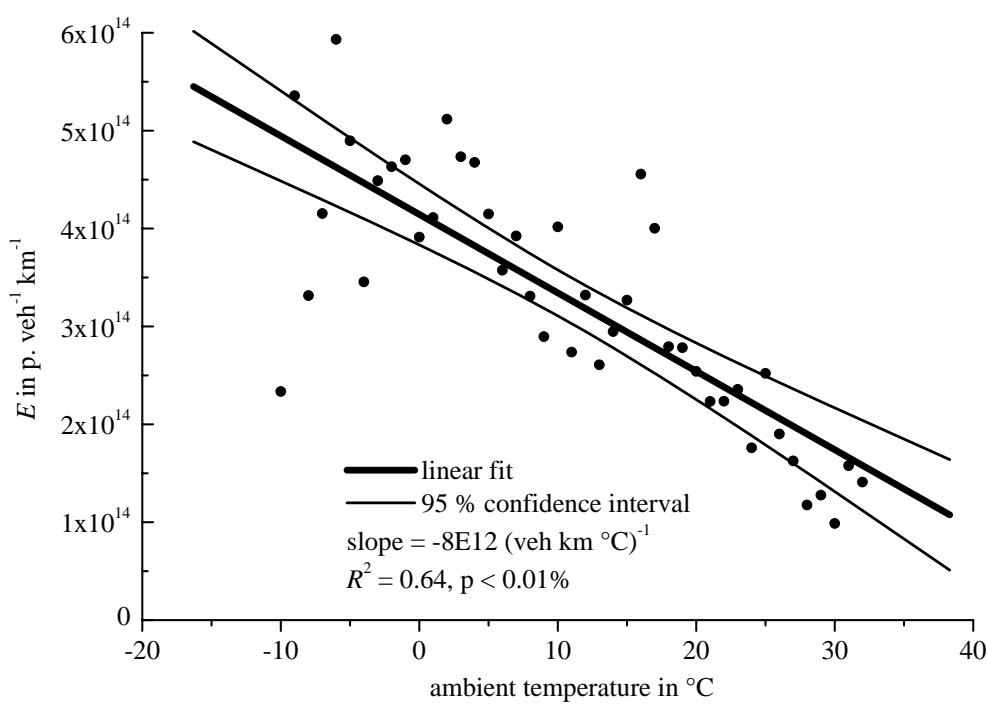

\section{emissions of motor traffic}

S. Klose et al.

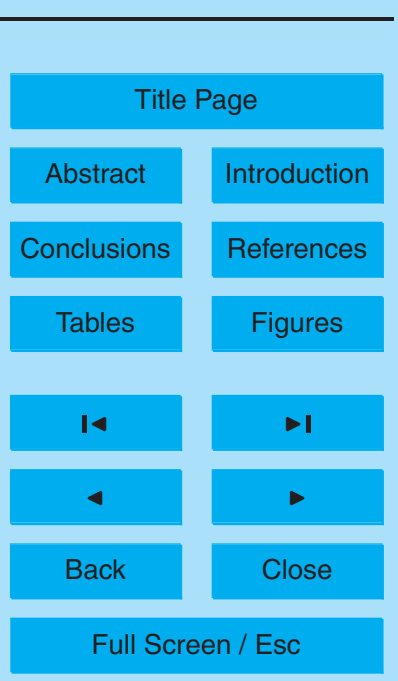

Printer-friendly Version

Interactive Discussion 


\section{ACPD}

9, 3763-3809, 2009

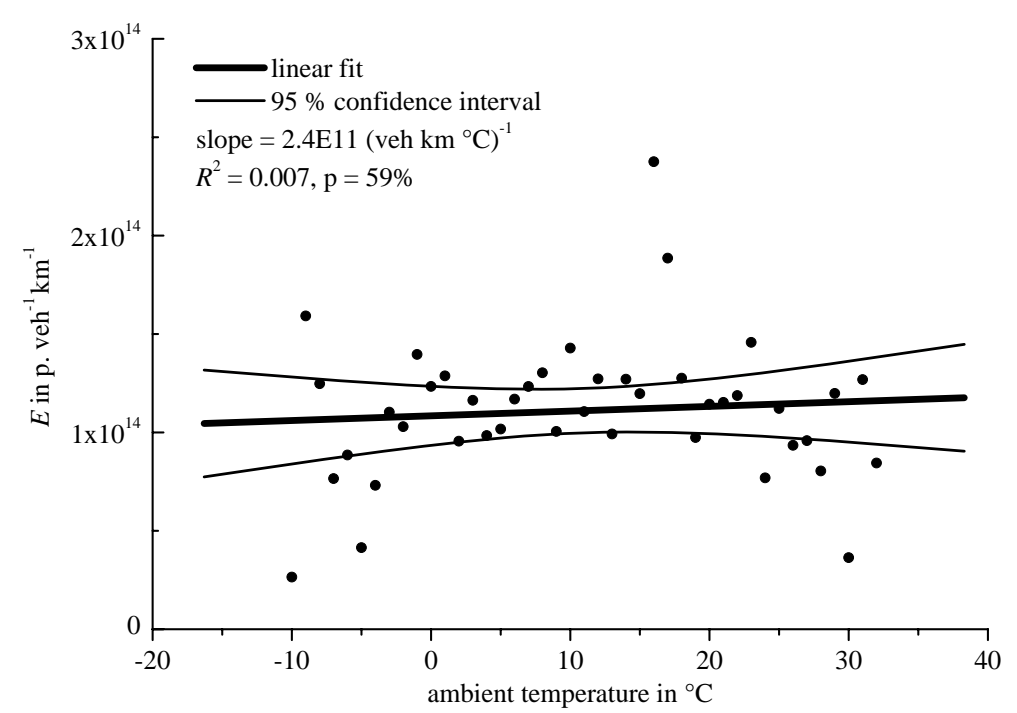

\section{Particle number emissions of motor traffic \\ S. Klose et al.}

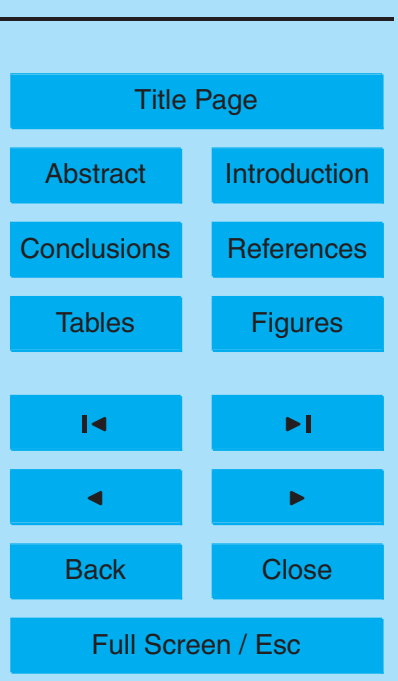

Printer-friendly Version

Fig. 9c. Particle number emission factor $\left(D_{p}\right.$ range $\left.30-100 \mathrm{~nm}\right)$ as a function of ambient temperature. Data coverage: 2005 and 2006, 06:00-10:00 LT.

Interactive Discussion 


\section{ACPD}

9, 3763-3809, 2009

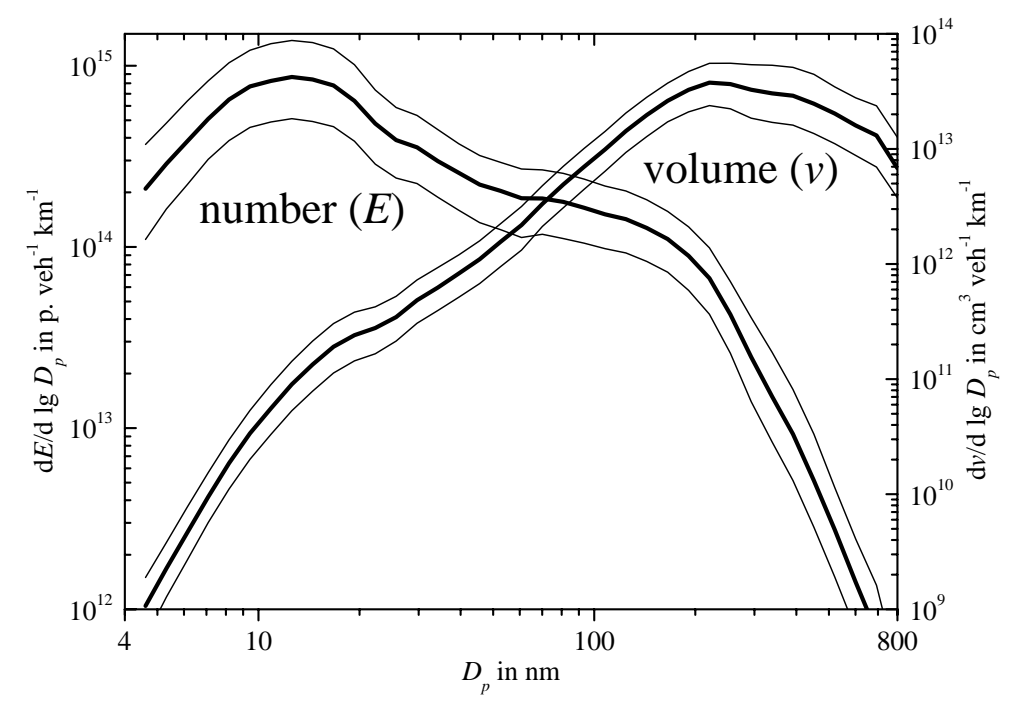

\section{Particle number emissions of motor traffic}

S. Klose et al.

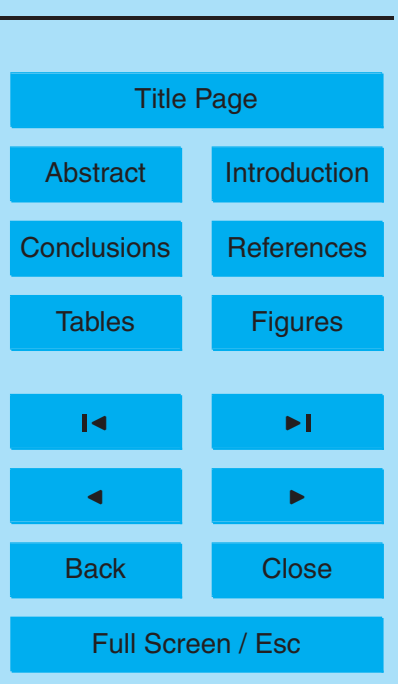

Printer-friendly Version

Fig. 10. Size distribution of the particle number and volume emission factors for an average vehicle. Thinner curves represent the 75 th and 25 th percentile distributions, respectively. Data coverage: 2005 and 2006, 06:00-10:00 LT.

Interactive Discussion 


\section{ACPD}

9, 3763-3809, 2009

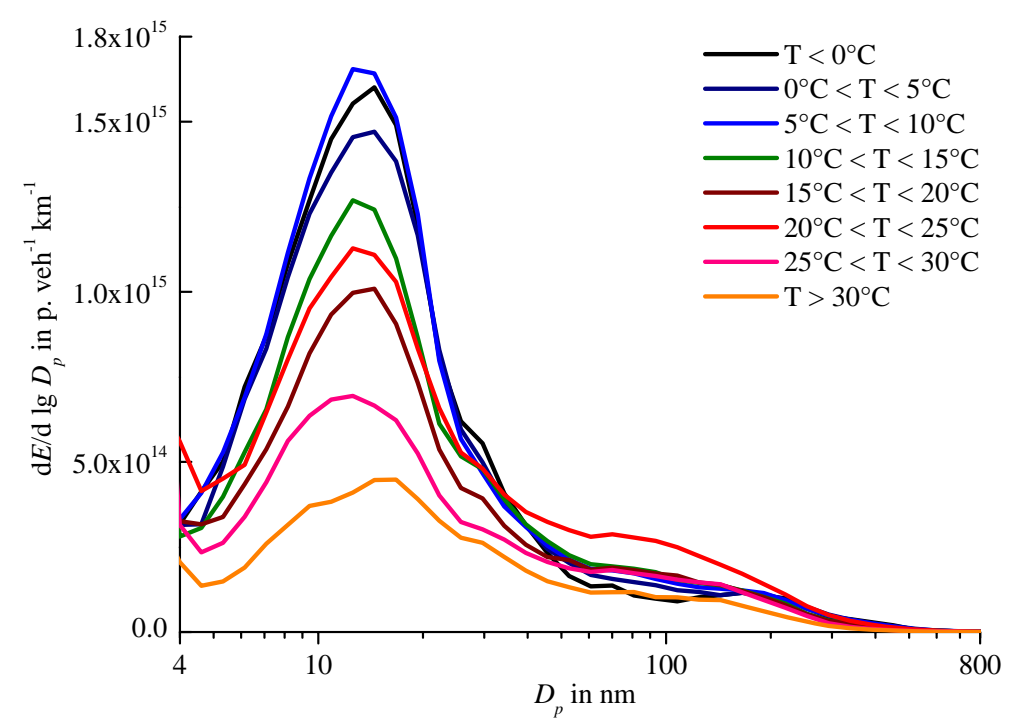

\section{Particle number} emissions of motor traffic

S. Klose et al.

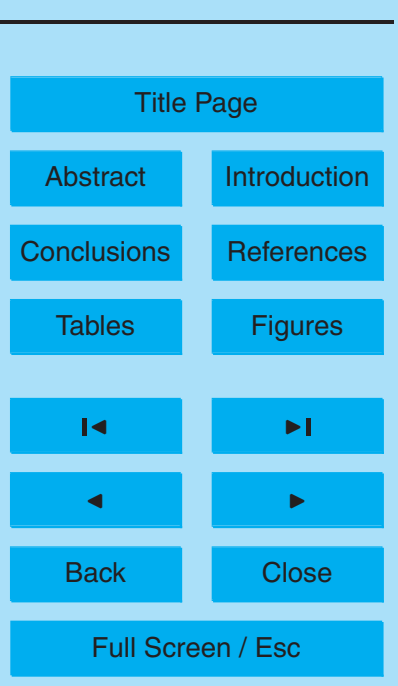

Printer-friendly Version

Fig. 11. Size distribution of the particle number emission factor of an average vehicle as a function of ambient temperature. Data coverage: 2005 and 2006, 06:00-10:00 LT.

Interactive Discussion 